\title{
SISMICIDADE DO NORDESTE DO BRASIL
}

\author{
JOAQUIM M. FERREIRA \\ Grupo de Geofísica - Departamento de Fisica Teórica e Experimental - Universidade Federal do Rio Grande do Norte \\ Caixa Postal $143-59.000-$ Natal - RN \\ MARCELOS. ASSUMPÇÃO ${ }^{1}$
}

Instituto Astronômico e Geofísico - Universidade de São Paulo

\begin{abstract}
A revised catalogue of earthquakes, which occurred in the Northeastern region of Brazil up to 1980 , is presented. Most of the data come from historical macroseismic information collected in old publications and newspapers. Recent instrumental data is used to derive empirical relations between magnitude and felt area in order to estimate $\mathrm{mb}_{\mathrm{b}}$ magnitudes for the events not recorded by seismographic stations. Macroseismic data for two large events (Pereiro 23.02.68, and Pacajus 20.11.80) are presented in detail. Epicentres of four recent events recorded at NAT were determined by combining the macroseismic and instrumental data and used to define a preliminary value of the ratio $K=V_{p} / V_{s}=1.77$ for the region under study. A swarm of activity at Parazinho, Rio Grande do Norte, was studied in more detail to estimate the parameter $b$ of the Gutenberg and Richter frequencymagnitude relation.
\end{abstract}

\section{INTRODUÇĀO}

Desde o trabalho de Capanema (1859) foram feitas várias compilações de eventos sísmicos ocorridos no território brasileiro tais como Gama (1910), Sadowski et al. (1978) e Berrocal et al. (1981). Há ainda a contribuição relevante dos trabalhos de Sampaio $(1916,1919$ e 1920) referentes aos eventos sísmicos ocorridos no Recôncavo Baiano. Tentativas de interpretação sismotectônica foram feitas por Branner $(1912,1920)$ e recentemente por Haberlehner (1978), Sadowski et al. (1978) e Hasui \& Ponçano (1978). No entanto os dados sismológicos disponíveis até agora eram insuficientes para estudar-se a sismotectônica do Nordeste.

O objetivo deste trabalho é apresentar, de maneira sintética, um levantamento dos eventos sísmicos ocorridos no Nordeste do Brasil até 31 de dezembro de 1980. Para este levantamento foram coletados e analisados dados macrossísmicos e instrumentais e, na medida do possivel, foram avaliadas intensidades e magnitudes para formação de um catálogo de sismos. Espera-se que este catálogo sirva de base para estudos futuros da sismicidade e simotectônica do Nordeste do Brasil. Naturalmente, o levantamento apresentado neste trabalho não é completo e provavelmente muitos outros dados serão coletados em pesquisas futuras sobre a sismicidade do Nordeste.

\section{DADOS MACROSSIŚMICOS}

Os dados macrossísmicos são uma descrição dos efeitos da passagem das ondas sísmicas produzidas por um sismo: tanto sensações em pessoas e animais, como efeitos em objetos, construções e na própria natureza. O estudo dos eventos ocorridos antes da invenção do sismógrafo só pode ser feito através da análise destes dados macrossísmicos. Ainda hoje, em regiões como o Brasil, com baixa densidade de estações sismográficas e onde os epicentros instrumentais muitas vezes são determinados utilizando-se estações distantes, o uso de dados macrossísmicos continua sendo de grande valia para uma melhor determinação de epicentros.

O material com dados macrossísmicos utilizado neste trabalho foi, inicialmente, o mesmo usado por Berrocal et al. (1979). Posteriormente foram coletadas informações adicionais, principalmente em bibliotecas públicas e arquivos de jornais de Recife, Caruaru, Maceió, João Pessoa, Natal e Fortaleza. Sempre que possivel tentou-se obter as informações originais referentes a cada evento. Foram realizadas também algumas entrevistas com pessoas que haviam sentido tremores em anos recentes.

Resumidamente, o tratamento dos dados macrossísmicos é constituído das seguintes etapas: identificação do evento a que pertencem; localidades afetadas; efeitos sentidos em cada localidade; avaliação das intensidades; mapa da área afetada e respectivas isossistas; determinação do epicentro macrossísmico e avaliação da magnitude através da área afetada. Para a avaliação das intensidades foi utilizada a escala Mercalli Modificada (Wood \& Neumann, 1931). O cálculo da magnitude a partir da área afetada será visto posteriormente. Na prática, os dados nem sempre permitem a realização de todas as etapas do tratamento; em alguns casos, nem mesmo é possível obter com precisão a data de ocorrência do evento.

A seguir são apresentados, de forma resumida, dois exemplos de eventos sísmicos onde foi possível realizar todas as etapas do tratamento de dados macrossísmicos: o evento de Pereiro (CE) de 23 de fevereiro de 1968, cujo epicentro provável na realidade se encontra no Estado do Rio Grande do Norte, e o de Pacajus (CE) de 20 de novem- 
bro de 1980. As informações dos efeitos macrossísmicos, resumidas abaixo, foram baseadas principalmente em notícias de jornais da época. É provável que muitas das notícias tenham sido exageradas. Foi tomado todo cuidado possível para confirmar as notícias, seja através de jornais independentes seja através de relatórios específicos. No caso do sismo de Pacajus foi possível contar também com informações fornecidas pelo geólogo J.A. Mioto, do Instituto de Pesquisas Tecnológicas de São Paulo, que visitou várias cidades afetadas.

\section{a. PEREIRO}

Data: 23.02 .1968 às 11 h $23 \mathrm{~min}$, hora local (12h $23 \mathrm{~min}$, horário de verão).

Epicentro provável: $6,09^{\circ} \mathrm{S} 38,440 \mathrm{~W}$

Intensidade máxima observada: VII MM (Fig. 1)

Área afetada: $84,0 \times 10^{3} \mathrm{~km}^{2}$ (Fig. 2)

Magnitude: $4,6 \mathrm{mb}_{\mathrm{b}}$

Localidades afetadas:

Antenor Navarro (PB) - garrafas "dançaram" nas prateleiras e muitas chegaram a cair. Crato $(C E)$ - sentido na Agência do Banco do Brasil; não houve pânico; localidade onde foi sentido mais fortemente na zona do Cariri. Dr. Severiano $(R N)$ - numerosas casas desabaram ou tiveram suas paredes rachadas; abertura de fendas na terra; 1500 pessoas desabrigadas; pânico geral. Ererê (CE) - desabamento de casas; população em polvorosa; um morto (ao fugir do desabamento caiu de mau jeito). Frade (RN) - todas as casas dos trabalhadores desabaram; casa grande com enormes fendas nas paredes; queda de telhas; feridos. ICó (CE) - "trovões" seguidos de tremores; apareceram grandes rachaduras em algumas casas. Jaguaribe (CE) - "trovões" seguidos de tremores; apareceram grandes rachaduras em algumas casas; jogou telhas dos telhados à distância de quase $0,5 \mathrm{~m}$; pessoas hospitalizadas com crise nervosa. Jardim (RN) - fenderamse as paredes de 30 a 40 casas. Junco (RN) - fendas em $90 \%$ dos prédios; algumas casas ruíram; caixão de farinha partiu-se ao meio; feridos; população em fuga. Jurema (RN) - casa com enorme fenda; desabou casa de farinha. Mundo Novo (RN) - algumas casas inabitáveis. Orós (CE) - tremor precedido de estrondos; tremor rápido; estremecimento em janelas; casas fenderam-se; danos em um prédio; pânico. Pau dos Ferros (RN) - ambiente de pânico. Pereiro (CE) Tremores precedidos de estrondos como se fossem trovões; objetos tremeram; panelas remexeram-se e cairam do fogão; casa inteira tremeu; provocou fendas, pequenas e grandes, em $40 \%$ dos prédios; paredes rachadas de cima a baixo; paredes empenadas; queda de reboco de residências e da igre-

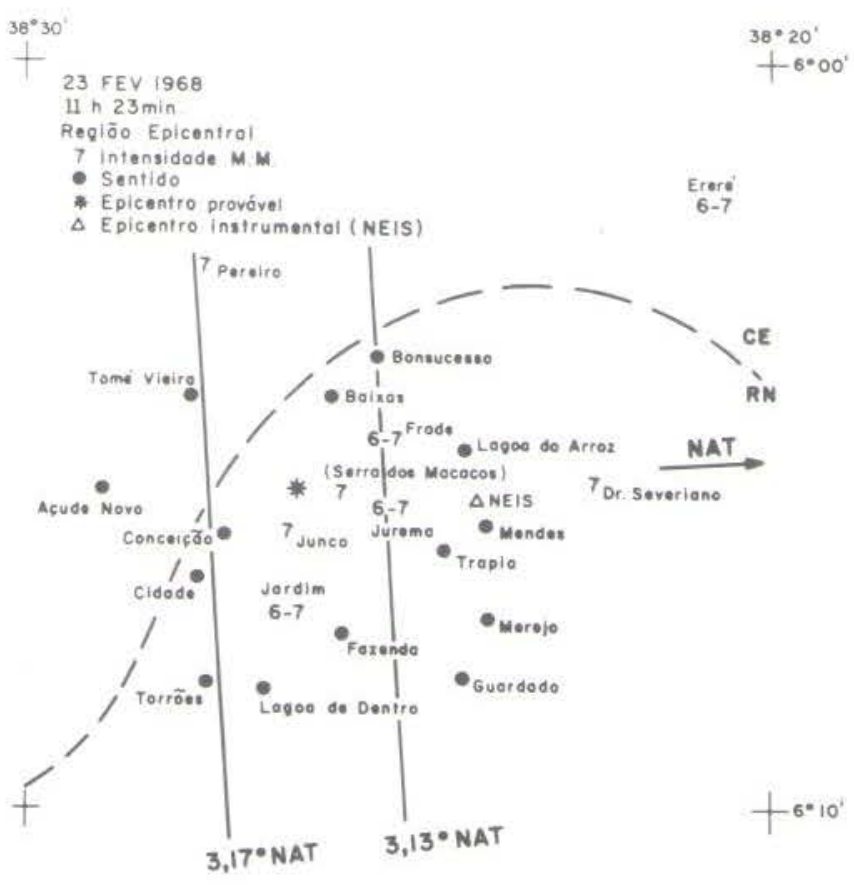

7 Sลิด Miquง

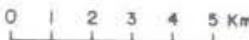

Figura 1 - Região epicentral do sismo de Pereiro (CE) de 23.02. 1968 (11h $23 \mathrm{~min}, \mathrm{~h}$. local). As linhas 3,170 NAT e $3,13^{\circ}$ NAT são as distâncias em graus à estação de Natal, calculadas a partir dos sismogramas de NAT, usando-se a tabela Herrin e levando-se em conta as incertezas na medida de S.P em NAT.

ja; vigas dos telhados afastadas; deslizamento de telhas; várias brechas nas paredes do ginásio; centenas de pessoas correram para as ruas aos gritos; população desabrigada; mais de 1000 pessoas abandonaram a cidade. S. Miguel (RN) rachaduras em várias casas; destruiu parte de alguns prédios; ruas com fendas enormes nos "paralelos". Senador Pompeu (CE) - algumas casas apresentaram pequenas rachaduras; não houve pânico. Serra dos Macacos (RN) - várias casas caidas e muitas apresentaram rachaduras; aparecimento de estreitas fendas em zona de talude; população em fuga. Viraúna (PB) - população saiu às ruas assombrada.

Causou alguns prejuízos (danos) nas seguintes localidades: Açude Novo, Baixo do Queirós, Campos, Flores, Mamoeiro, São José, São Paulo, Tomé Vieira e Trigueiro, no Ceará; Baixos, Bonsucesso, Cidade, Conceição, Fazenda, Guardado, Lagoa de Dentro, Mendes, Merejo, Teixeira, Torrões e Trapiá, no Rio Grande do Norte. 


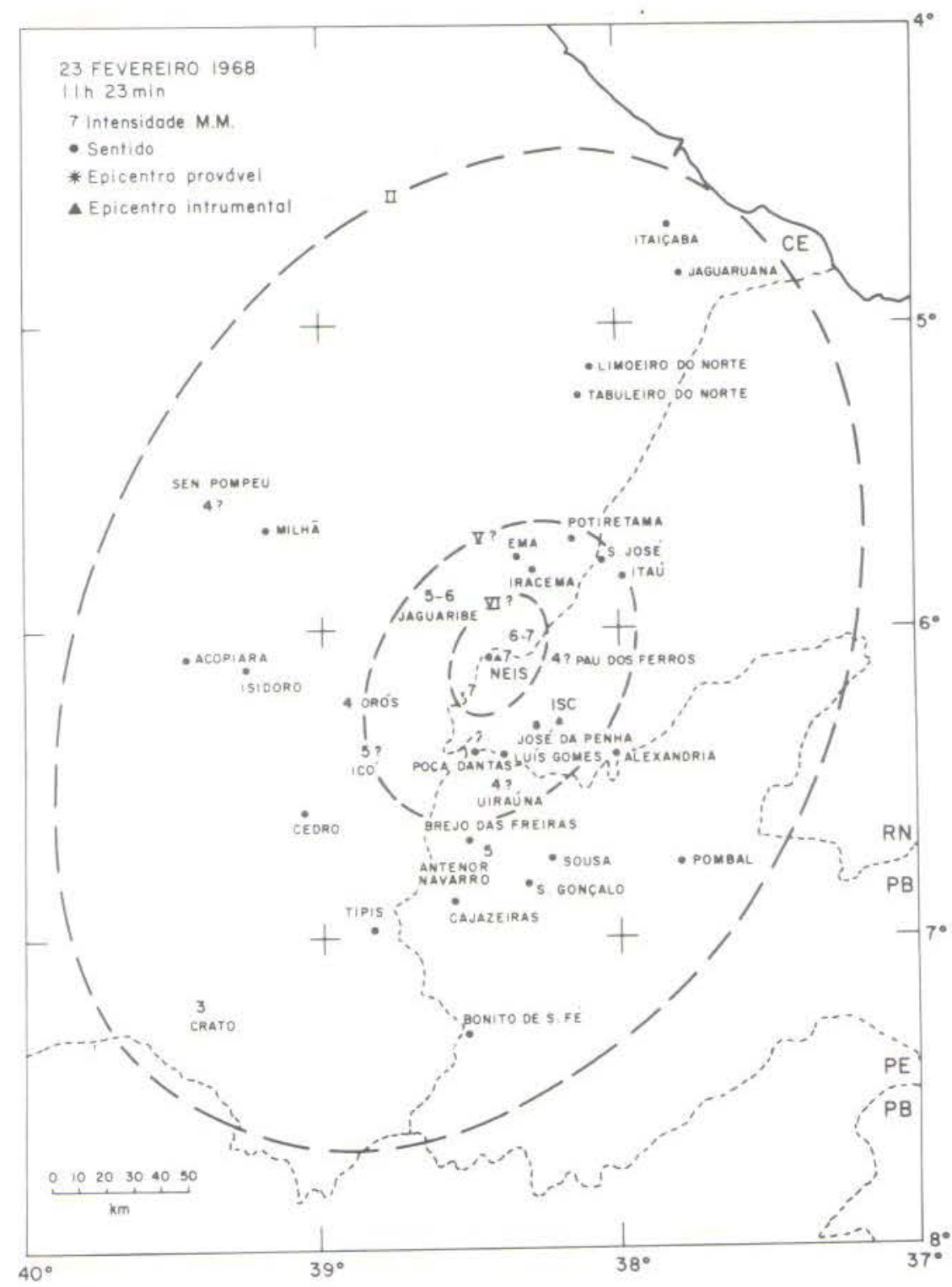

Figura 2 - Area afetada e isossistas do sismo de Pereiro (CE) de $23.02 .196811 \mathrm{~h} 23 \mathrm{~min} .$, hora local).

Sentido também nas seguintes localidades: Carrancuda, Cedro. Conro, Ema, Iracema, Isidoro, Itaiçaba, Jaguaruana, Limoeiro do Norte, Milhã, Palmeira dos Indios, Potiretama, Tabuleiro do Norte e Tipis, no Ceará; Aroeiras, Bonito de Santa Fé, Brejo das Freiras, Cajazeiras, Poço Dantas, Pombal, Saco das Piabas, São Gonçalo e Sousa, na Paraiba; Alexandria, Itaú, José da Penha, Luis Gomes e São José dos Gatos, no Rio Grande do Norte.

\section{b. PACAJUS}

Data: 20.11 .1980 às $00 \mathrm{~h} 29 \mathrm{~min}$, hora local Epicentro provável: $4,30 \circ \mathrm{S} 38,40$ W
Intensidade máxima observada: VII MM (Fig. 3) Área afetada: $1 \times 10^{6} \mathrm{~km}^{2}$ (Fig. 4)

Magnitude: $5,2 \mathrm{mb}$

Localidades afetadas:

Ceará:

Aracati - tremor sentido por muitos. Baturité - causou medo em muitos e pânico em alguns; durou $3 \mathrm{~s}$. Brito - várias casas destruídas (queda e trinca de reboco); rachaduras nas paredes da igreja até 2 dedos de largura, atravessando de um lado a outro; rachaduras acompanhando os tijolos; paredes não engatadas afastaram-se ligeiramente. Capistrano - causou medo em muitos e pânico em alguns; durou $3 \mathrm{~s}$. 


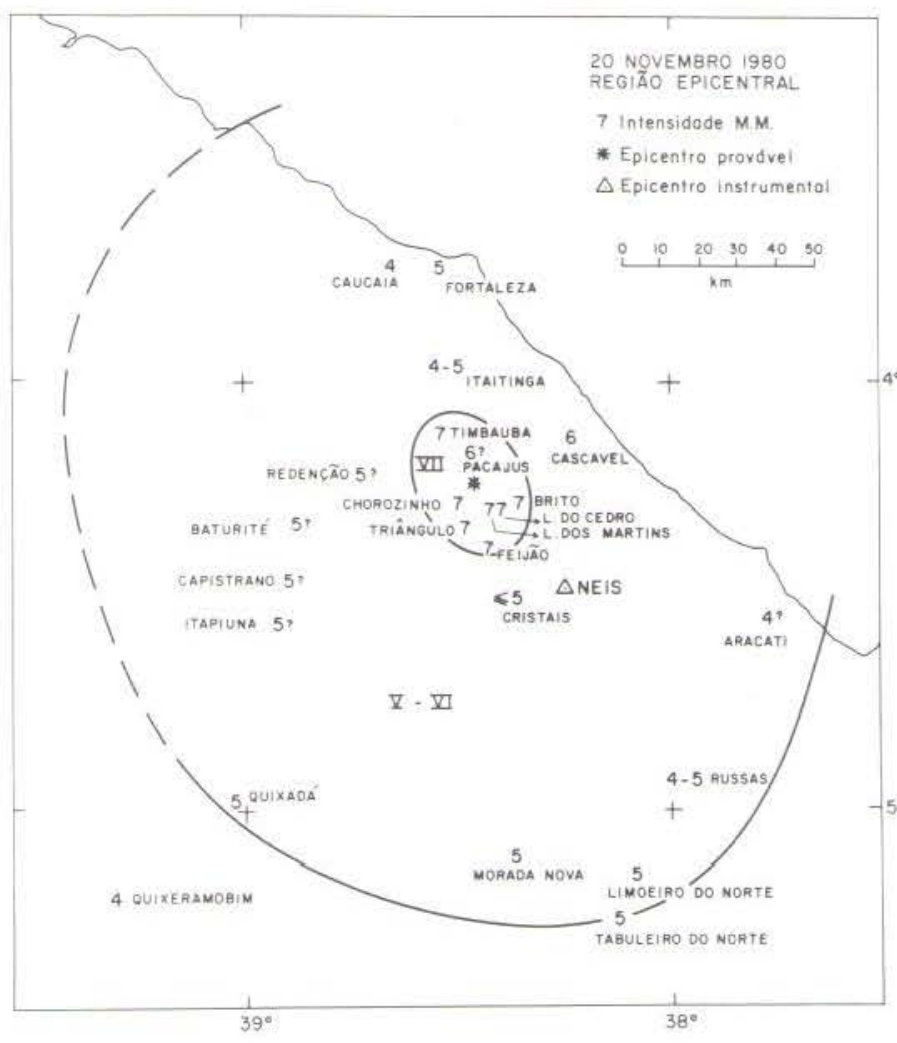

Figura 3 - Região epicentral, com isossistas, do sismo de Pacajus (CE) de 20.11 .1980 (00h $29 \mathrm{~min}, \mathrm{~h}$. local). A linha cheia indica uma maior confiabilidade no traçado da isossista.
Cascavel - muitos sentiram e sairam às ruas; algumas casas apresentaram pequenas trincas; nenhum dano sério. Catu pessoas ficaram desabrigadas. Caucaia - acordou doentes no hospital, ventilador descoordenou-se; ferramentas cirúrgicas tiniram; pequeno deslocamento de objetos em mesas e estantes; camas mexeram-se; som cavo e profundo semeIhante a um trovão estrangulado. Chorozinho - maior parte das construções com rachaduras nas paredes e queda de reboco; forro da igreja começou a desabar, poucas trincas; várias casas de taipa ruiram. Feijão - casas desabaram; pessoas feridas e um morto (?). Fortaleza - acordou muita gente; paredes, assoalho, portas e forro de madeira rangeram; balançou lustres; parou relógio de pêndulo; redes sacolejaram; copos tilintaram; deslocou objetos e mobílias; derrubou louças e quadros das paredes; quebrou vidraças; dezenas de casas e edifícios com rachaduras nas paredes (?): sentido principalmente em prédios de apartamentos. Iguatu - sentido apenas em algumas áreas da cidade; portas tremeram. Itapiuna - causou medo em muitos e pânicos em alguns; durou 3 s. Lagoa de Cedro - várias casas foram ao chão; desabamento de paredes de tijolo inteiro; partes de paredes bastante deslocadas e inclinadas; porta envergada; trincas em pilares; rachaduras em muros; queda de reboco; 200 desabrigados com medo das rachaduras das casas. Lagoa do Martins - casa desabou quase totalmente; famílias desabrigadas. Limoeiro do Norte - curto tremor de terra que durou mais de $3 \mathrm{~s}$; a cidade praticamente toda acordou. Mombaça - sentido por algumas pessoas. Morada Nova balançou quadro; caiu um objeto de prateleira; telhado "chacoalhou", derrubando poeira; telhas afastaram-se e

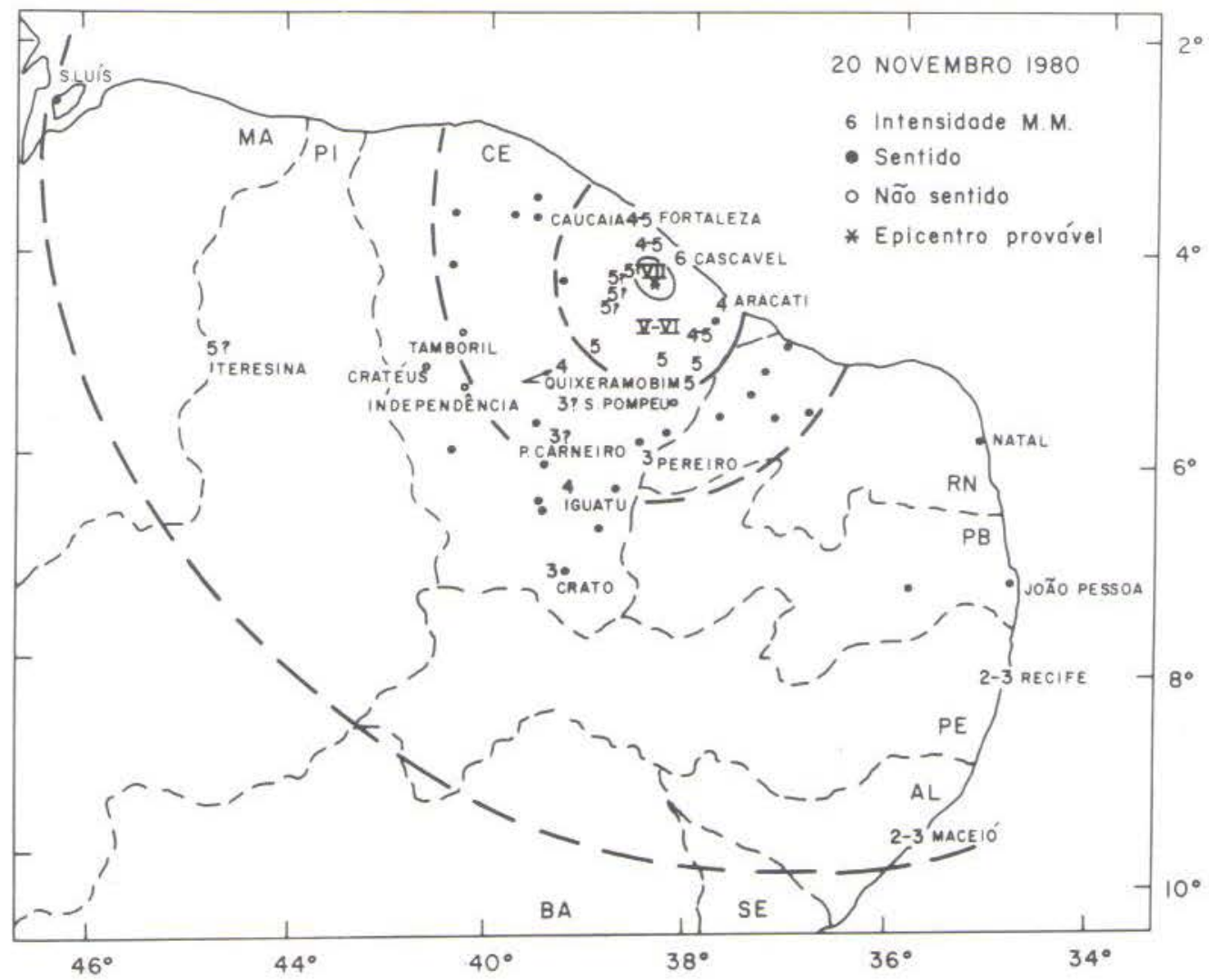

Figura 4 - Area afetada e isossistas do sismo do Pacajus (CE) de 20.11.1980 (OOh 29 min., h. local). 
cairam (?). Pacajus - dezenas de casas no município foram atingidas; duas fábricas com enormes rachaduras em suas paredes; diversas (?) casas com paredes rachadas. Pereiro sentido por algumas pessoas. Piquet-Carneiro - sentido por algumas pessoas. Quixadá - população acordada por fortes tremores; rachaduras (?) e quebra de telhas e caibros em residências; desmaios e garrafas quebradas nos bares; muitas pessoas nada sentiram. Quixeramobim - algumas pessoas sentiram o abalo; não houve pânico; numa das ruas todas as casas sofreram avarias (?); sentiu-se barulho nas telhas. $R e$ denção - causou medo em muitos e pânico em alguns; durou $3 \mathrm{~s}$. Russas - muitas pessoas sentiram; nenhum estrago em construção; pequeno recalque em dique não compactado. Senador Pompeu - sentido por algumas pessoas. Tabuleiro do Norte - telhas afastaram-se e cairam. Timbaúba tetos desabados e rachaduras nas paredes, na maioria das casas; dois feridos; casa nova rachada; paredes da igreja rachadas; telhado da escola parcialmente caido. Triângulo de Quixadá - rachaduras a $45^{\circ}$ de lado a lado em parede de um tijolo; queda de azulejos; trinca em piso de ladriIhos, soltando alguns; a maior parte das construções com rachaduras nas paredes e queda de reboco.

\section{Pernambuco:}

Recife - sentido nos edifícios causando trepidação nas cadeiras e louças e, em alguns locais, em pias.

\section{Alagoas:}

Maceió - sentido por algumas pessoas, num raio de quase $10 \mathrm{~km}$, no bairro do Prado; sentido claramente em alguns prédios onde pessoas desceram em pânico.

\section{Piauf:}

Teresina - sentido em vários pontos da cidade (prédios e casas); vidraças quebradas e queda de reboco na Casa dos Estudantes; sofás tremeram, telhas caíram; muitas pessoas, de vários pontos da cidade, foram para a rua; passou desapercebido pela maior parte da população.

Sentido também nas seguintes localidades: Acopiara, Alto Santo, Araras, Canindé, Cariús, Choró dos Macacos, Cristais, Crato, Fiúza, Ibaretama, Icó, Iracema, Irauçuba, Itaiçaba, Itaitinga, Itapajé, Itapipoca, Jaguaribe, Jaguaruana, Juatama, Juazeiro do Norte, Jucás, Lavras da Mangabeira, Oticica, São João do Jaguaribe, S. Luis, Sítio Albano, Sobral, Tauá, Umirim e Vila Rosa, no Ceará; São Luis, no Maranhão; Campina Grande e João Pessoa, na Paraiba; Açu, Apodi, Areia Branca, Governador Dix-Sept Rosado, Mossoró, Natal e Upanema, no Rio Grande do Norte.

\section{DADOS INSTRUMENTAIS}

Devido ao pequeno número de estações sismográficas operando no Brasil ( 3 até o início da década de 70; de 20 a
30 atualmente) e à distribuição inapropriada das mesmas, com apenas quatro estações no Nordeste (Natal, Sobradinho, Itataia e Itaparica), somente eventos sísmicos de razoavel magnitude, que ocorrem no Nordeste, podem ser registrados por estações brasileiras ou do exterior.

Para a compilação dos dados instrumentais apresentados neste trabalho, foram analisados sismogramas da Estação de Natal (NAT), da Estação Sismográfica de Brasília e de algumas outras operadas pela Universidade de Brasília. Incluem-se também dados da Rede Sismográfica de Sobradinho fornecidos pelo Instituto Astronômico e Geofísico da Universidade de São Paulo. Dados obtidos por estações do exterior foram extraídos de boletins do ISC (International Seismological Centre) e dos EDR (Earthquake Data Report) do U.S. Geological Survey.

A não ser a série de eventos de Parazinho (RN) registrados por NAT, que será apresentada mais adiante, são relativamente poucos os registros instrumentais de eventos sísmicos ocorridos no Nordeste devido aos fatores acima mencionados. Tais dados são de extrema importância tanto para a detcrminação do epicentro quanto da magnitude.

\section{Magnitude}

Uma das escalas de magnitude mais utilizadas é a escala $\mathrm{m}_{\mathrm{b}}$ que usa as ondas de volume, definida por Guten. berg \& Richter (1956). No entanto, o cálculo de $m_{b}$ com a tabela de Gutenberg \& Richter (1956) não é confiável quando se utilizam dados de estações a distâncias epicentrais menores que $20^{\circ}$. Normalmente o valor de $\mathrm{mb}_{\mathrm{b}}$ de estações próximas no Brasil, é maior que o calculado com estações a distâncias telessísmicas. Para superar esse problema têm sido propostas várias fórmulas regionais para cálculo da magnitude com estações a menos de 200 de distância. Recentemente, Assumpção (1983) propôs a seguinte fórmula para o cálculo da magnitude regional no Brasil, denominada $m_{R}$ :

$$
m_{R}=\log V+2,3 \log R-2,28 \quad 200 \leqslant R \leqslant 1500 \mathrm{~km}
$$

onde $V$ é a velocidade do solo $(\mu / \mathrm{s})$ correspondendo à máxima amplitude de registro da onda $\mathrm{Pe} R$ a distância da estação ao epicentro (em $\mathrm{km}$ ). Esta fórmula fornece valores mais próximos do valor $m_{b}$ telessísmico que outras fórmulas de magnitude regional quando aplicadas a sismos brasileiros. Neste trabalho a magnitude instrumental adotada foi $\mathrm{mb}$, quando havia dados telessísmicos, ou $\mathrm{mR}$ quando os dados eram de estações regionais.

\section{Medidas de S-P (NAT)}

A medida de S.P (diferença entre o tempo de chegada da onda S e o da P) permite, em princípio, obter a distância epicentral. Para tanto basta utilizar uma tabela que forneça o tempo de percurso das ondas S e P em função da distância epicentral e da profundidade do foco. Uma tabela muito utilizada é a J-B (Jeffreys \& Bullen, 1940). 
Variações regionais da estrutura da crosta e manto superior, podem significar grandes diferenças entre os tempos de percurso reais e os da tabela J-B, principalmente para distâncias regionais. Erros de dezenas de quilômetros podem ser cometidos com os dados de S-P quando se usa a tabela J-B sem testar se ela é válida para determinada região. $\mathrm{Na}$
Tabela 1 são comparados os valores da distância epicentral $(\Delta \mathrm{O})$ utilizando-se a tabela $\mathrm{J}-\mathrm{B}$ com os valores de $\Delta^{\mathrm{O}}$ adotados para alguns eventos. Como se pode ver a tabela J-B fornece valores muito parecidos com os adotados mostrando que, em princípio, a mesma pode ser utilizada para a região nordestina.

Tabela 1 - Comparação das distâncias epicentrais calculadas pelas tabelas Herrin (adotada) e $\mathrm{J}$-B para alguns sismos registrados por NAT.

\begin{tabular}{|c|c|c|}
\hline EVENTO & $\Delta\left(^{\circ}\right)$ adotada & $\Delta\left(^{\circ}\right) \mathrm{J}-\mathrm{B}$ \\
\hline Pereiro (1968) & $3,15 \pm 0,02$ & $3,13 \pm 0,03$ \\
Caruaru (1967) & $2,42 \pm 0,02$ & $2,45 \pm 0,03$ \\
Toritama (1974) & $2,25 \pm 0,09$ & $2,30 \pm 0,09$ \\
Parazinho (1973) & $0,79 \pm 0,02$ & $0,82 \pm 0,02$ \\
\hline
\end{tabular}

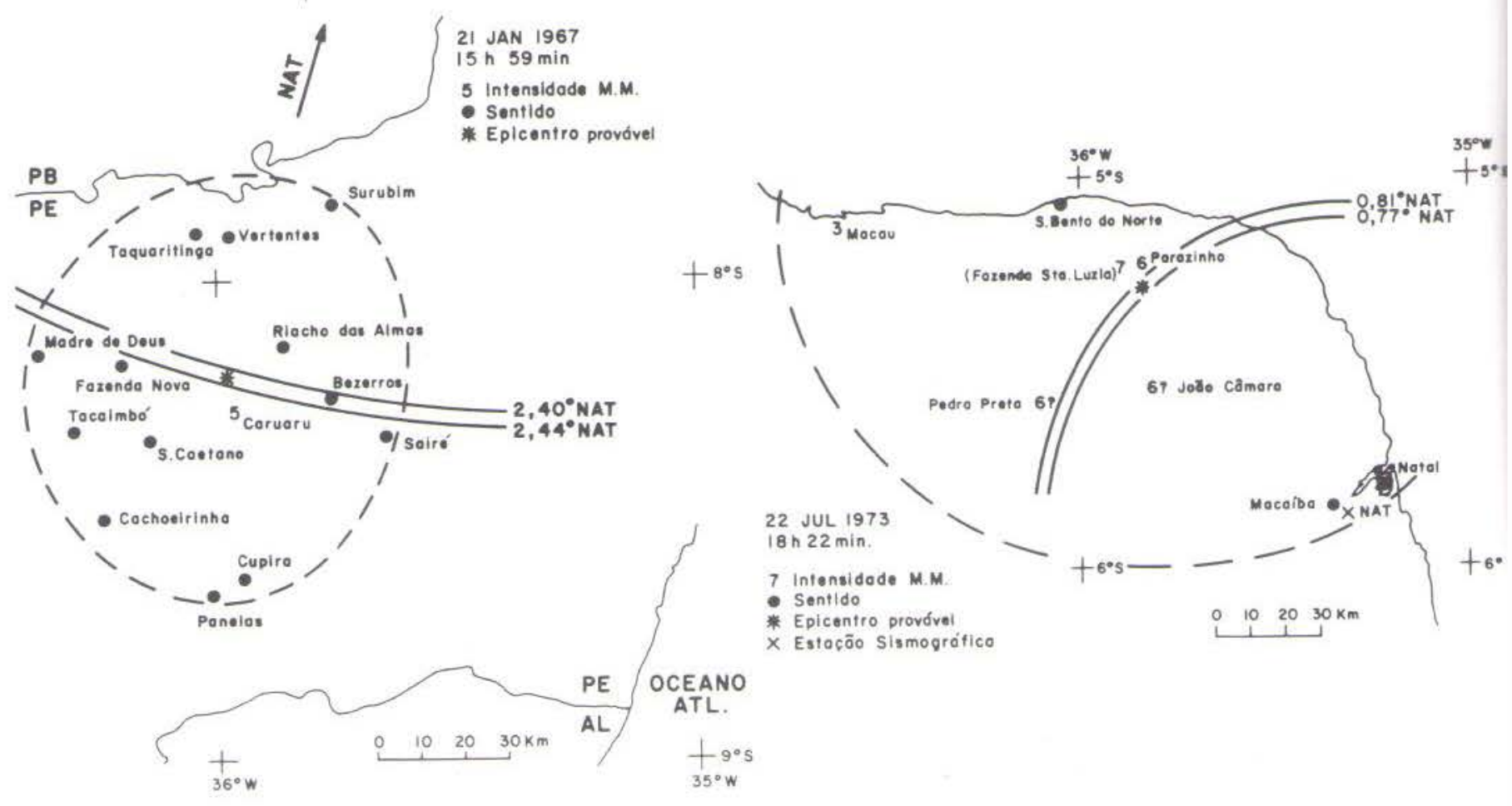

Figura 5 - Area afetada pelo sismo de Caruaru (PE) de 21.01.1967 mostrando a faixa onde deve estar o epicentro, de acordo com os dados instrumentais (S-P), utilizando-se a tabela de Herrin.
Figura 6 - Área afetada pelo sismo de Parazinho (RN) de 22.07. 1973 mostrando a faixa onde deve estar o epicentro, de acordo com os dados instrumentais (S-P), utilizando-se a tabela de Herrin. 
20 OUT 1974

$18 \mathrm{~h} 37 \mathrm{~min}$

5 Intensidade M.M.

- Sentido

* Epicentro provável

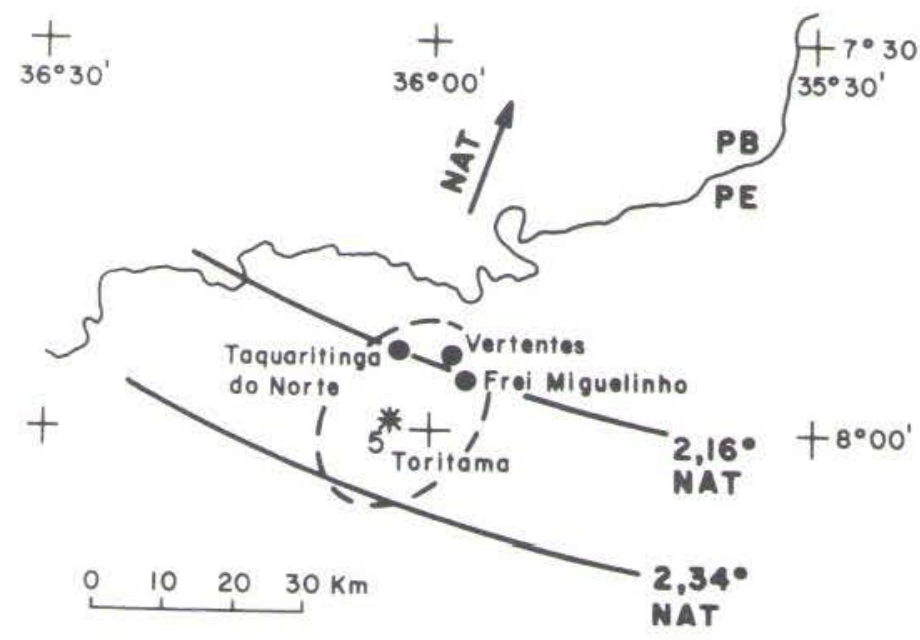

Figura 7 - Área afetada pelo sismo de Toritama (PE) de 20.10. 1974 mostrando a faixa onde deve estar o epicentro. de acordo com os dados instrumentais (S-P), utilizando-se a tabela Herrin.
Decidiu-se no entanto, utilizar as tabelas de Herrin (1968) para onda $P$, visto ser a mesma mais moderna e geralmente dar melhores resultados que a tabela J-B para eventos próximos. Com os dados dos eventos acima calculou-se o valor médio da constante $K=V_{P} / V_{S}$, onde $V_{p} e$ $V_{S}$ são as velocidades das ondas $P$ e $S$. Supondo-se que a razão $V_{p} / V_{S}$ seja constante nas camadas da crosta e manto superior, vê-se que $K=t_{s} / t_{p}$ onde $t_{s}$ e $t_{p}$ são os tempos de percurso das ondas $P$ e $S$. Ou ainda $K=1+\left(t_{s}-t_{p}\right) / t_{p}$. Obtem-se $K$, então, com $P-S\left(=t_{S}-t_{p}\right)$ lido nos sismogra. mas e $t_{p}$ fornecido pela tabela de Herrin (1968) para a distância epicentral do evento.

Uma vez determinado um valor preliminar de $\mathrm{K}$, os epicentros podem ser melhor definidos combinando-se os dados instrumentais (S-P) com as informações macrossísmicas. Ou seja, para os eventos acima referidos os epicentros e o valor de $\mathrm{K}$ foram obtidos iterativamente. Os epicentros usados estão nas Figs. 1, 5, 6 e 7.

A Fig. 8 mostra o valor final de $K=1,769 \pm 0,007$ cujos dados estão na Tabela 2. Este valor de $\mathrm{K}$ poderá ser usado futuramente para determinar distâncias epicentrais de outros sismos registrados por estações do Nordeste. Na Tabela 2 os valores da profundidade focal (h) não são bem determinados e foram adotados com base nos dados macrossísmicos (Ferreira, 1983).

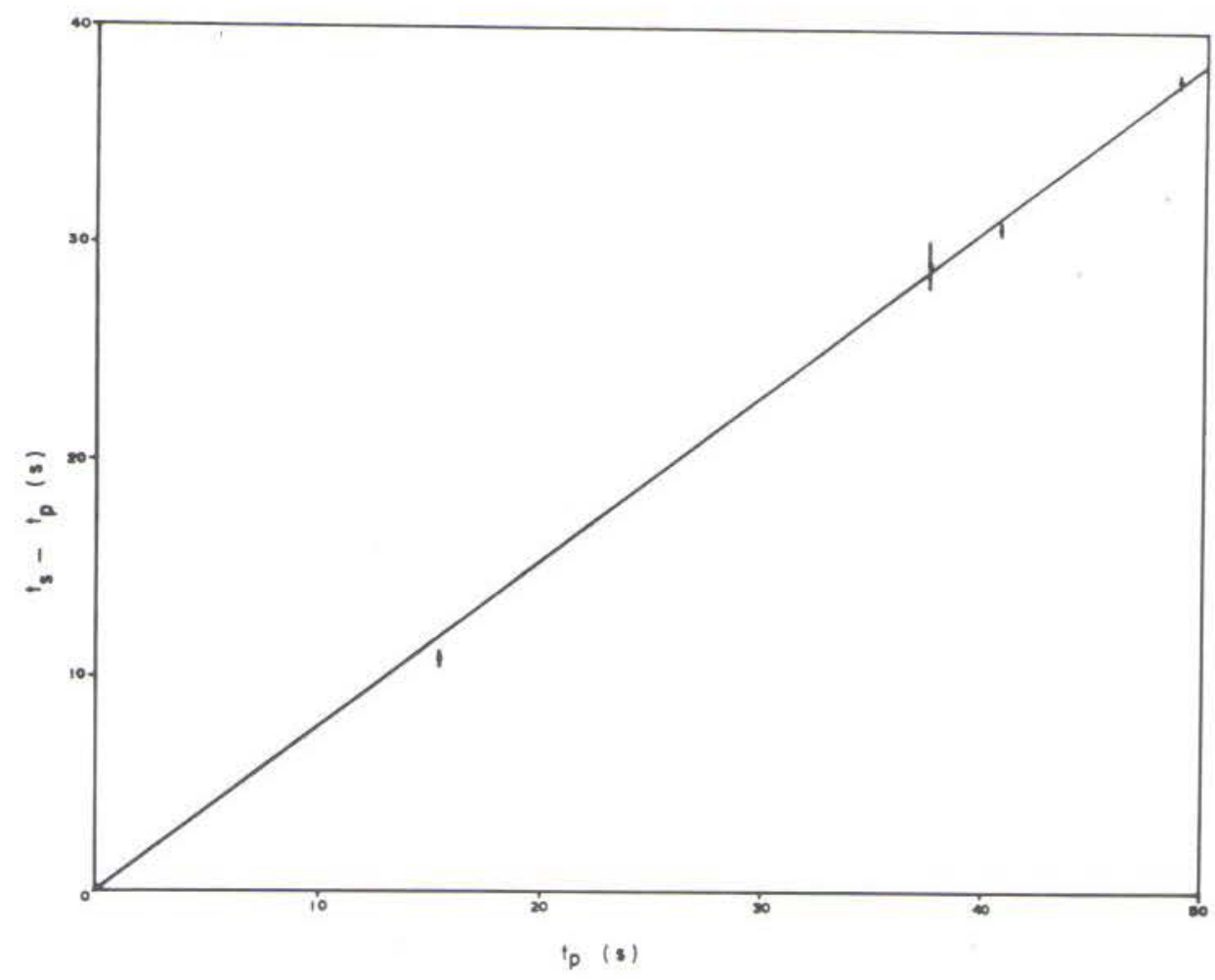

Figura 8 - Reta de ajuste de ts-tp em função de tp de acordo com os dados da Tabela 2. O coeficiente angular dessa reta é 0,769 o que equivale a $K=1,769$. 
Tabela 2 - Parâmetros dos sismos utilizados no cálculo da constante $\mathrm{K}=\mathrm{V}_{\mathrm{p}} / \mathrm{V}_{\mathrm{s}}$.

\begin{tabular}{|c|c|c|c|}
\hline EVENTO & $\mathrm{S}-\mathrm{P}(\mathrm{s})$ & $\mathrm{h}(\mathrm{km})$ & $\mathrm{tp}(\mathrm{s})$ \\
\hline Pereiro (1968) & $37,7 \pm 0,2$ & 15 & 48,82 \\
Caruaru (1967) & $30,8 \pm 0,2$ & 5 & 40,75 \\
Toritama (1974) & $29,1 \pm 1,0$ & 5 & 37,46 \\
Parazinho (1973) & $10,9 \pm 0,2$ & 15 & 15,45 \\
\hline
\end{tabular}

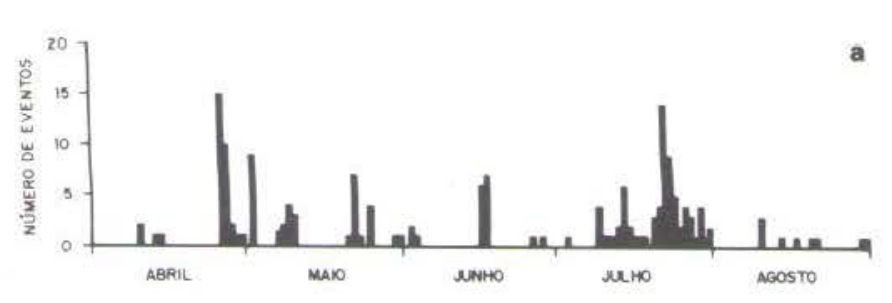

\section{Sismos de Parazinho}

No ano de 1973 vários sismos foram sentidos no município de Parazinho (RN) sendo que três deles chegaram a ser sentidos em Natal, a aproximadamente $90 \mathrm{~km}$ do epicentro. Numa análise dos registros da estação de Natal (NAT) no período compreendido entre 10 de abril e 31 de agosto de 1973 verificou-se que NAT registrou 165 eventos ocorridos em Parazinho (Fig. 9a).
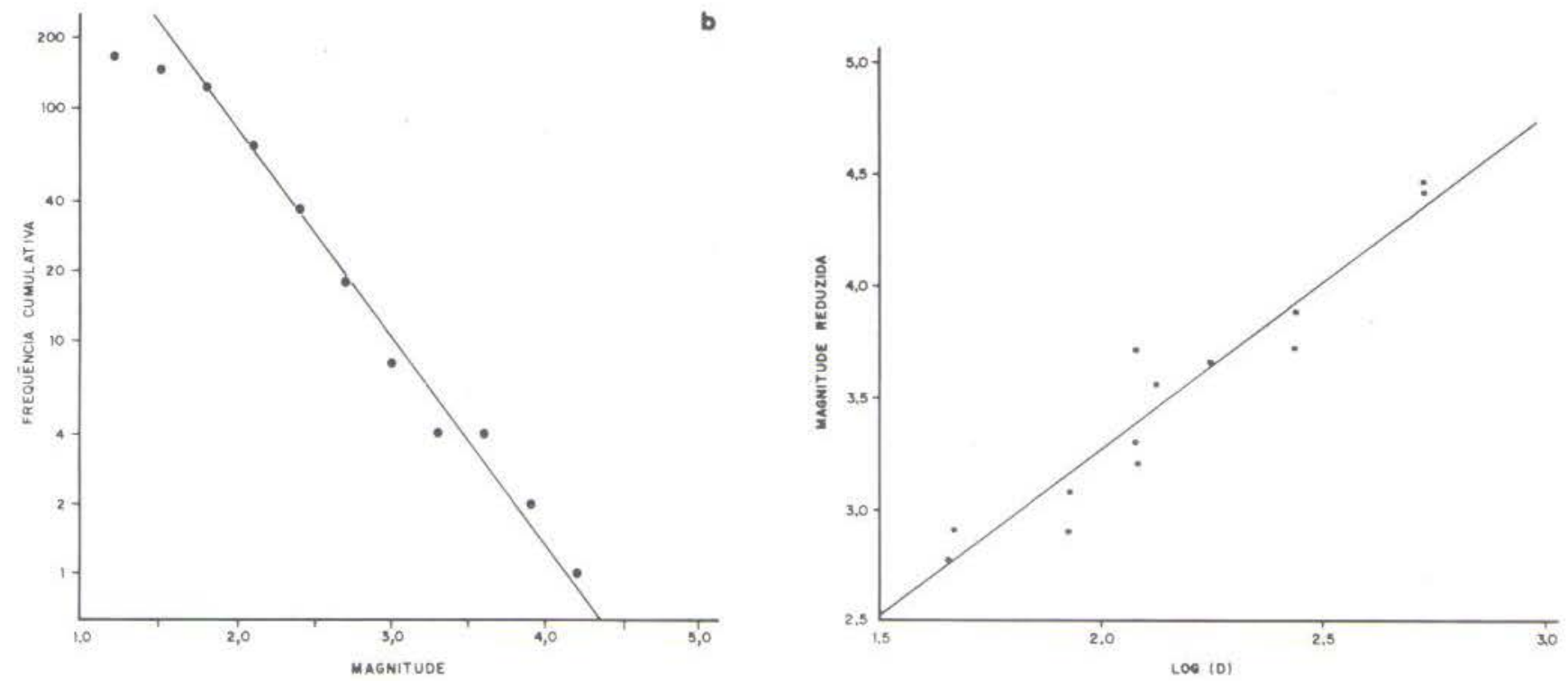

Figura 9 - a) Distribuição temporal mostrando o número de eventos ocorridos em Parazinho (RN), por dia, entre 01.04 .1973 e 31.08.1973.

b) Freqüência cumulativa da seqüência de abalos ocorridos em Parazinho (RN) em 1973.

Figura 10 - Correlação entre a magnitude $m_{R}$ e a duração D. E usada a magnitude reduzida $Y$, normalizada para a distância de $200 \mathrm{~km}, Y=m_{R}-0,0012$ (R-200), onde $R$ é a distância epicentral ern km, para se eliminar o efeito da distância na correlação entre a magnitude $e$ a duração. 
Um único evento, o de 22 de julho às $18 \mathrm{~h} 22 \mathrm{~min}$ (hora local), foi registrado a distâncias telessísmicas e teve magnitude $m_{b}$ calculada em 4,1. Para os demais eventos a magnitude pode ser obtida de diversas formas: a) através de $m_{R^{i}}$ b) através da duração do sinal, e c) através da relação $A S / \mathcal{V}$.

a. Para o cálculo de $m_{R}$ para os eventos de Parazinho supôs-se que a fórmula fosse válida para distâncias epicentrais menores que $200 \mathrm{~km}$. Os dados atualmente disponíveis ainda não permitem verificar a validade dessa extensão da fórmula de $m_{R}$.

b. Para sismos próximos como os de Parazinho, freqüentemente os sismogramas ficam saturados não sendo possível o cálculo direto da magnitude. Nestes casos a magnitude $m_{R}$ pode ser estimada empiricamente através da correlação entre magnitudes e a duração do sinal em NAT. Definindo-se a duração do sinal como o tempo decorrido entre chegada da onda $\mathrm{P}$ e o último pulso nítido de $3 \mathrm{~mm}$ de amplitude pico a pico, foi obtida a seguinte fórmula:

$m_{R}(D)=0,1( \pm 0,3)+1,5( \pm 0,1) \log D+0,0012( \pm$

$0,0004) R$ (c. corr $=0,96$ )

onde a duração do sinal $D$ é dada em segundos e a distância epicentral $R$ em km. A Fig. 10 mostra a relação entre $m_{R}$ e a duração D. Na obtenção dessa fórmula foram utilizados quatro sismos de Pereiro (CE), quatro de Parazinho (RN), três de Toritama (PE), um de São Luis do Curu (CE) e um de Caruaru (PE). Não foram usados unicamente sismos de Parazinho para que se pudesse determinar o termo de variação com a distância tornando a fórmula acima de aplicação mais geral.

c. Vários sismos de Parazinho tinham magnitudes tão baixas que a amplitude da onda $\mathrm{P}$ era muito pequena para obter-se um valor confiável de $m_{R}$. Nestes casos a magnitude foi estimada através de uma relação empírica entre a velocidade do solo $\mathrm{V}$ devido à onda $\mathrm{P}$ e a amplitude $\mathrm{A}_{\mathrm{S}}$ da onda $\mathrm{S}$. Tal método só é válido considerando-se eventos de um mesmo epicentro (e provavelmente mesmo mecanismo focal) registrados por uma mesma estação. Nessas condições a relação entre $\mathrm{V}$ e $A_{S}$ deve ser linear da forma:

$$
V=\alpha A_{S}
$$

onde o coeficiente $\alpha$ é obtido correlacionando-se os pares de valores $\mathrm{V}$ e $\mathrm{A}_{\mathrm{S}}$ com uma reta que passa pela origem, através do método dos mínimos quadrados. A Fig. 11 mostra os dados usados para obter-se $\alpha$ Desta maneira $m_{R}$ pode ser estimado com $V$ obtido através de $A_{S}$.

O valor final da magnitude para os eventos de Parazinho foi adotado seguindo os seguintes critérios em ordem

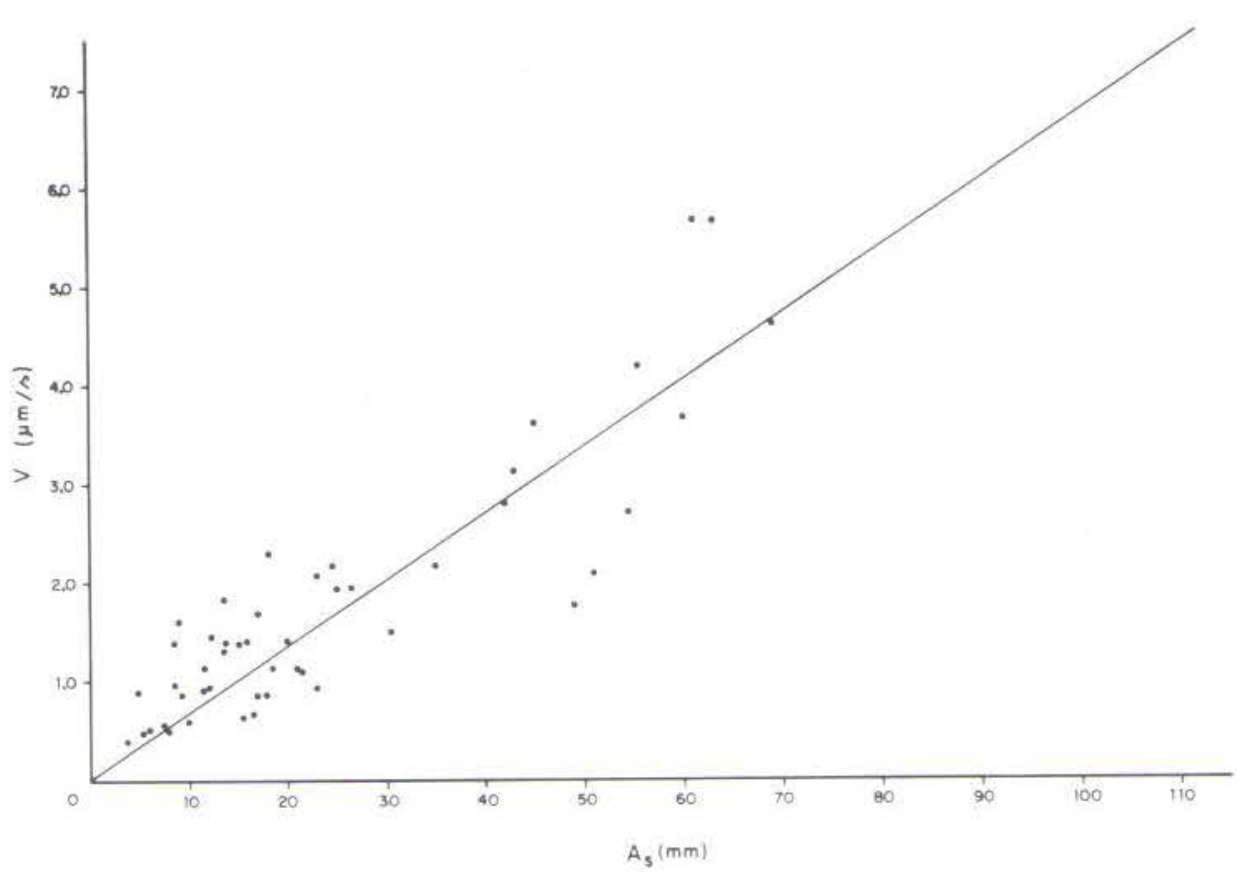

Figura 11 - Grárico da correlação $V \times A_{S}$. 
de prioridade: a magnitude é igual a uma média entre $\mathrm{mb}_{\mathrm{b}}$ e $m_{R}$ quando ambos existam; igual a $m_{R}$ quando é possível calcular $m_{R}$; uma média ponderada das magnitudes estimadas pela duração e amplitude da onda $S$, usando-se como pesos os inversos dos desvios padrões, obtidos quando do cálculo das respectivas correlações com $m_{R}$.

A relação entre o logarítimo do número de eventos $\mathrm{N}$, ocorridos numa dada região, de magnitude maior ou igual a $\mathrm{m}$, num determinado período de tempo, é geralmente linear (Gutenberg \& Richter, 1954):

$$
\log N=a-b m
$$

onde $a$ depende do nível de sismicidade e $b$ é geralmente próximo de 1. Na Fig. 9b é apresentado o gráfico de log $N$ em função de $m$ para os eventos de Parazinho. $O$ valor de $b$, obtido por mínimos quadrados é:

$$
b=0,90 \pm 0,05
$$

Este valor poderá ser comparado, futuramente, ao de outras regiões do Nordeste para estudos de regionalização sismotectônica e avaliação de risco sísmico.

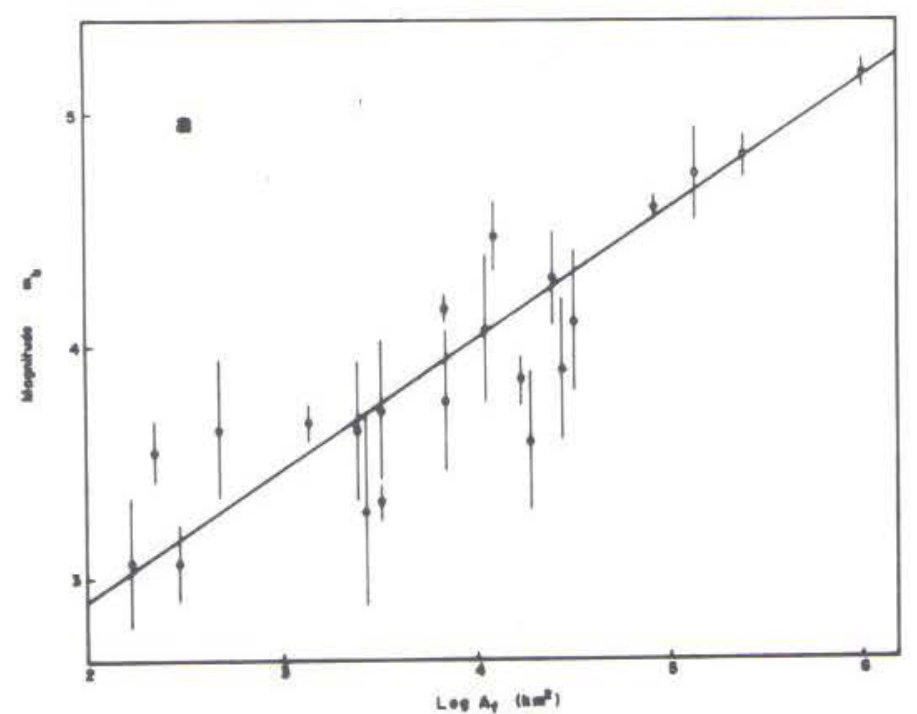

Figura 12 - a) Correlação entre a magnitude $m_{b} e$ a área afetada total, para sismos ocorridos em várias regiōes do Brasil.

para os quais foi possivel determinar a área total afetada Af ou a área dentro da isossista IV MM.

\section{LISTAGEM}

A listagem no anexo é uma sintese de todas as informações relevantes relativas a cada evento sismico, ocorridos

\section{MAGNITUDE E ÁREA AFETADA}

Como já foi dito, com exceção dos eventos de Parazinho, são poucos os registros instrumentais de eventos sísmicos ocorridos no Nordeste do Brasil. Na prática, poucos são os eventos para os quais é possivel determinar diretamente a magnitude. No entanto pode-se estimar a magnitude de um evento sísmico desde que se conheçam relações empíricas entre a magnitude e os dados macrossismicos do evento. $A$ área total afetada pelo sismo $\left(A_{f}\right)$ ou a área dentro da isossista IV $\left(A_{\mid V}\right)$ são geralmente bem correlacionadas com a sua magnitude e pouco dependentes da profundidade focal (Nuttli et al., 1979). Como os dados disponiveis só do nordeste são muito poucos, para o cálculo da relação entre $\mathrm{mb}_{\mathrm{b}} \mathrm{e}$ a área afetada foram utilizados todos os dados disponíveis para o Brasil (Fig. 12). Usando uma relação linear obtém-se:

$$
\begin{aligned}
& m_{b}=1,80( \pm 0,10)+0,56( \pm 0,02) \log A_{f} \in \\
& m_{h}=2,33( \pm 0,20)+0,53( \pm 0,05) \log A_{I V}
\end{aligned}
$$

Com essas relações é possível obter a magnitude para os sismos mais antigos não registrados instrumentalmente, mas

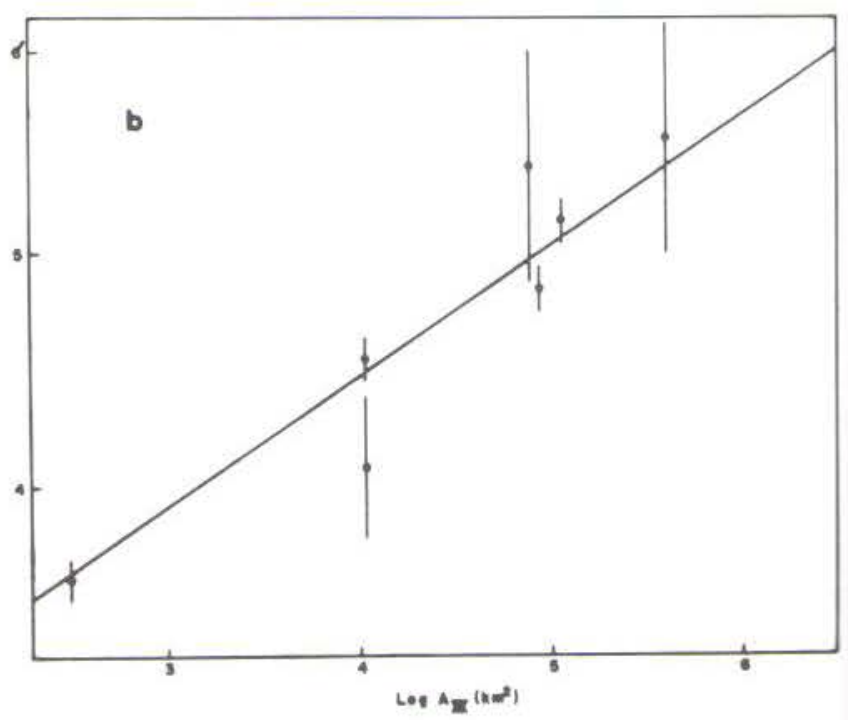

b) Correlação entre a magnitude $m_{b}$ e área afetada IV, para sismos ocorridos em várias regiōes do Brasil.

no Nordeste, até 31 de dezembro de 1980.

$\mathrm{Na}$ listagem, a hora local é a hora oficial brasileira (GTM-3h, referente ao meridiano de 450W) mesmo nos anos em que houve horário de verão.

As coordenadas geográficas são as coordenadas do epicentro, quando foi possivel determiná-lo. Caso contrário trata-se das coordenadas da localidade mais afetada ou da 
principal localidade em que o sismo foi sentido. 0 erro na determinação dos epicentros foi estimado de acordo com os dados macrossísmicos disponíveis (só área afetada e algumas intensidades; área afetada e isossistas) levando-se em conta que o epicentro está na região de maior intensidade. A ausência de um valor para o erro do epicentro não significa que este é bem preciso, mas apenas que não existiam dados para tal estimativa (geralmente sismos noticiados em uma só localidade).

A coluna "INT. MM" é a intensidade do sismo na escola Mercalli Modificada (Wood \& Neumann, 1931), correspondente à maior intensidade observada de que se tem notícia.

Os eventos sísmicos foram classificados em 5 categorias, dependendo da quantidade e qualidade das informações disponíveis (coluna "CAT"), seguindo a classificação sugerida por Berrocal et al. (1981).

A. sismo com dados macrossísmicos que permitem construir mapa de isossistas e determinar o epicentro com boa precisão.

B. sismo com dados que permitem determinar a área afetada, avaliar intensidades e determinar um epicentro aproximado.

C. sismo com informações certas sobre suas ocorrências, permitindo às vezes avaliar intensidades. $\mathrm{A}$ área afetada e o epicentro podem não estar bem determinados.

D. evento sísmico duvidoso, isto é, há dúvidas quanto ao local, data ou mesmo sobre a confiabilidade da fonte utilizada.

I. dado instrumental, quando só são disponíveis registros sismográficos sem dados macrossísmicos.

As magnitudes $\mathrm{mb}_{\mathrm{b}}$ constantes da listagem foram calculadas ou estimadas por um dos seguintes métodos:

TIPO MÉTODO

0: $\quad m_{b}$ telessísmico (Gutenberg \& Richter, 1956)

1: $\quad m_{R}$, estimativa de $m_{b}$ com estações regionais

2: $\quad$ média de valores de $m_{b}$ e $m_{R}$

3: $\mathrm{mb}_{\mathrm{b}}$ estimado pela área afetada

4: estimativa aproximada de $\mathrm{mb}$ pela Intensidade Máxima $\mathrm{I}_{0}$, supondo que $\mathrm{I}_{\mathrm{O}}$ corresponda à maior intensidade observada, e supondo profundidade focal de poucos quilômetros:

$m_{b}=1,21+0,45 I_{0}$ (Assumpção \& Burton, 1983).

A área afetada (coluna "A. AFET.") representa a área total de percepção, isto é, a área dentro da isossista II $\mathrm{MM}$, a não ser quando estiver explicitamente indicado como "área IV" na coluna "COMENTÁRIOS (FONTE)".

$\mathrm{Na}$ última coluna são apresentados alguns comentá. rios relevantes e é citada a principal fonte utilizada para cada sismo, não sendo necessariamente a única e nem a que contém todas as informações. No caso do sismo de Pereiro de 1968, por exemplo, foram utilizadas informações de 39 fontes distintas.

\section{CONCLUSÕES}

O mapa da Fig. 13 dá uma idéia da sismicidade do Nordeste. O sismo de maior magnitude no Nordeste, foi o de Pacajus (CE) de 1980 com $m_{b}=5,2$. A máxima intensidade de que se tem notícia foi VII MM, tendo já ocorrido na Bahia (Recôncavo), no Ceará (Pereiro e Pacajus) e no Rio Grande do Norte (Parazinho e Riachuelo). Os estados de maior atividade sísmica são Ceará, Rio Grande do Norte e Bahia (principalmente Recôncavo Baiano).

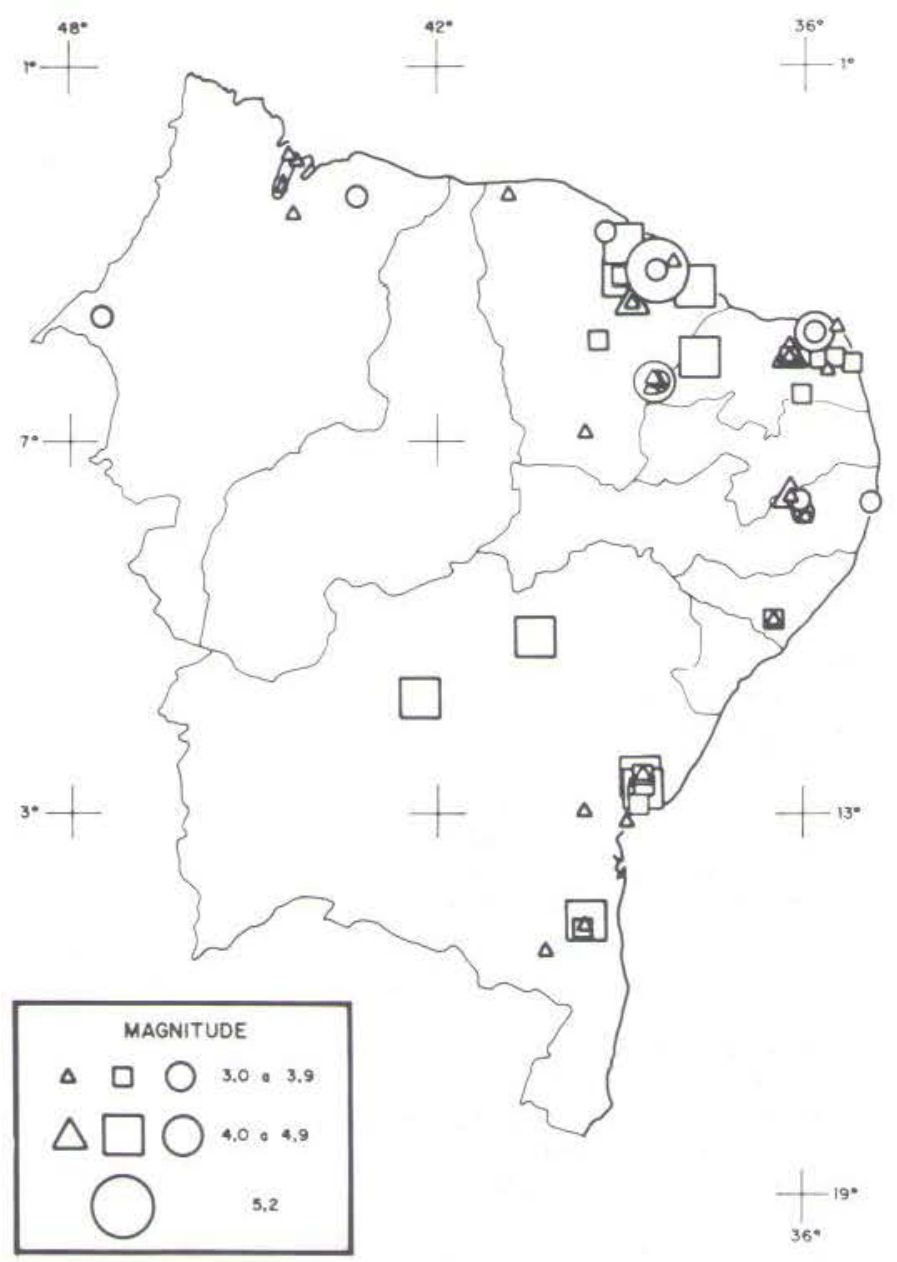

Figura 13 - Distribuição dos epicentros dos sismos do Nordeste. Os símbolos representam as diversas formas de cálculo da magnitude: círculo, magnitude instrumental; quadrado, magnitude calculada através da área afetada; triângulo, magnitude calculada através da intensidade máxima observada.

A relação entre a sismicidade e a tectônica é bastante complexa. Aparentemente a bacia sedimentar do Parnaiba (estados do Piauí e Maranhão) é bem menos sismica que outras regiões. Grandes falhamentos, como o de Patos e de 
Pernambuco, existem no Nordeste mas a relação entre eles e os epicentros não é muito clara. Ainda não se tem evidência segura de reativação de qualquer das grandes falhas geológicas do Nordeste. Um estudo mais detalhado sobre a correlação entre sismicidade e geologia está em andamento (Ferreira, 1983). A listagem apresentada no anexo representa o catálogo mais completo dos dados disponíveis sobre sismos do Nordeste do Brasil até 1980 . Todos os sismos foram dimensionados, quer quanto a intensidade máxima quer quanto à magnitude, da maneira mais homogênea pos-

$\mathrm{m}_{\mathrm{b}}=1,21+0,45 \mathrm{I}_{\mathrm{o}}$

sível, ou seja, todas as magnitudes foram referidas a uma única escala $(\mathrm{mb})$, e as intensidades de todos os sismos foram avaliadas com os mesmos critérios na tentativa de diminuir a parte subjetiva da interpretação de intensidades.
Espera-se que este catálogo sirva de base inicial para interpretações sismotectônicas e avaliação de risco sísmico no Nordeste do Brasil.

\section{AGRADECIMENTOS}

Agradecemos aos colegas do Grupo de Sismologia do IAG - USP, em especial a Jesús Berrocal,pelas informações iniciais sobre sismos do Nordeste assim como pela contribuição na avaliação das intensidades. Apesar das intensidades terem sido avaliadas pela comparação de interpretações independentes de várias pessoas do IAG, a responsabilidade pelos valores adotados neste trabalho cabe unicamente aos autores. Agradecemos a J. A. Mioto, do IPT - São Paulo, que gentilmente forneceu informações sobre o sismo de Pacajus de 20.11.80.

Este trabalho teve apoio financeiro da Comissão $\mathrm{Na}$ cional de Energia Nuclear (CNEN), CAPES (bolsa PICD) e CNPq (bolsa no 30.0227/79).

\section{REFERÊNCIAS}

ALCÁNTARA, P. d'. - 1860 - Documentos relativos ao tremor de terra havido em Pernambuco em 1811. Rev. Inst. Hist. e Geog., Rio de Janeiro, 23: $401-406$.

ASSUMPÇĀO, M. - 1983 - A regional magnitude scale for Brazil. Bull. Seism. Soc. Am., 73! 237-246.

ASSUMPÇAO, M. e BURTON, P. W. - 1983 - Seimicity of Brazil. Em preparaç̃o.

BERROCAL, J., ASSUMPÇĀO, M., ANTEZANA, R., DIAS NETO, C.M., ORTEGA, R. e FRANÇA, H. - 1979 - Regionalizaçāo sísmica do Brasil. Relatório científico para a CNEN. IAG-USP.

BERROCAL, J., ASSUMPÇĀO, M. ANTEZANA, R., DIAS NETO, C.M., ORTEGA, R. e FRANÇA, H. - 1981 - Regionalização sísmica do Brasil. Relatório científico final para a CNEN, 399 pp.

BRANNER, J. C. - 1912 - Earthquakes in Brazil. Bull. Seismol. Soc. Am., 2: 105-117.

BRANNER, J.C. - 1920 - Recent earthquakes in Brazil. Bull. Seism. Soc. Am., 10: 90-104.

BRASIL, T.P.S. - 1863 - Ensaio Estatístico da província do Ceará. Tomo I. Pg. 51.

CAPANEMA, G. S. - 1859 - Quais as tradições ou vestígios geo 16 gicos que nos levam à certeza de ter havido terremotos no Brasil. Rev. Inst. Hist. Geogr. Bras., 22: 135-159.

CARVALHO, A. - 1916 - Terremotos no Brasil. Rev. Inst. Hist. e Geog. do RN, 15: $92-93$.

FERREIRA, J. M. - 1983 - Sismicidade do Nordeste do Brasil. Tese de mestrado, em preparação.

GAMA, A. - 1910 - Tremores de terra no Brasil e sua origem pro. vável. An. 10 Congr. Bras. Geog., 4: 153-178.

GUTENBERG, B. e RICHTER, C. F. - 1954 - Seismicity of the Earth and associated phenomena. Princeton U.P., 310 pp.

GUTENBERG, B. e RICHTER, C. F. - 1956 - Magnitude and ener- gy of earthquakes. Ann. Geofis., 9: 1-15.

HABERLEHNER, H. - 1978 - Análise sismotectônica do Brasil, notas explicativas e regióes correlacionadas. An. 2 \% Congr. Bras. Geol. Eng., 1: 297-329.

HASUI, Y, e PONÇANO, W.L. - 1978 - Geossuturas e sismicidade no Brasil, An, 20 Congr. Bras. Geol. Eng., 1: 331-338.

HERRIN, E. - $1968-1968$ seismological tables for P phases. Bull Seism. Soc. Am., 58, 4:1192-1241.

JEFFREYS, H. e BULLEN, K. E. - 1940 - Seismological tables. British Association for the Advancement of Science, London.

MEDEIROS, T. - 1965 - A terra tremeu em Natal. Rev. Inst. Hist. e Geog. do RN, 60: 67-72.

MELLO, J.A.T. - 1881 - Ephemerides Nacionais, Rio de Janeiro Tomos I e II.

NUTTLI, O.W., BOLLINGER, G.A. e GRIFFITHS, D.W. - $1979-$ On the relation between Modified Mercalli intensity and body wave magnitude. Bull. Seism. Soc. Am., 69: 893-910.

SADOWSKI, G.R., CSORDAS, S. M. e KANJI, M. A. - $1978-$ Sismicidade da plataforma brasileira. An. 30 ○ Congr. Bras. Geol. 5: 2347-2361.

SAMPAIO, T. - 1916 - Movimentos sísmicos na Bahia de Todos os Santos. An. 50 Congr. Bras. Geog.: 357367.

SAMPAIO, T. - 1920 - Tremores de terra na Bahia em 1919. de Todos os Santos. Rev. Inst. Geog. e Hist. da Bahia, 26, 45 211-222.

SAMPAIO, T. - 1920 - Tremores de terra na Bahia em 1919 Rev. Inst. Geog, e Hist. da Bahia, 27, 46:183-195.

WOOD, H. O. e NEUMANN, F. - 1931 - Modified Mercalli intensity scale of 1931. Bull. Seism. Soc. Am., 21:277-283.

Versão original recebida em Fev./1983; Versāo final, em Jun./1983. 
ANEXO

CATALOGO DE SISMOS DO NORDESTE OCORRIDOS ATÉ DEZ. 1980

\begin{tabular}{|c|c|c|c|c|c|c|c|c|c|c|c|c|c|c|c|c|}
\hline N. & ANO $\mathrm{MA}$ & ATA & DIA & H. & $\begin{array}{l}\text { LOCAL } \\
M S\end{array}$ & $\begin{array}{l}\text { COORD. } \\
\text { LAT. S }\end{array}$ & $\begin{array}{l}\text { GEOGR. } \\
\text { LONG. } W\end{array}$ & $\begin{array}{c}\text { ERRO } \\
\mathrm{km}\end{array}$ & LOCALIDADE E & ESTADO & INT. MM & CAT & $\begin{array}{l}\text { MAGN } \\
m b\end{array}$ & $\begin{array}{l}\text { NITUDE } \\
\text { tipo }\end{array}$ & ${ }_{10}^{\text {A. AFET. }} \mathrm{km}^{2}$ & $\begin{array}{c}\text { COMENTKRIOS } \\
\text { (FONTE) }\end{array}$ \\
\hline 1 & 1666 & & & & & & & & SALVADOR & $B A$ & & 0 & & & & tsunamis? (SAMPAIO 1916) \\
\hline 2 & 1709 & & & & & & & & & BA & & D & & & & (SADOWSKI et al.1978) \\
\hline 3 & 1720 & 11 & 23 & & & & & & SALVADOR. & $8 \mathrm{~A}$ & & D & & & & (CARVALHO 1916) \\
\hline 4 & 1721 & 03 & 20 & & & & & & SALVADOR & BA & & D & & & & (SAMPAIO 1916) \\
\hline 5 & 1724 & 01 & 041 & 073 & 30 & 13.00 & 38.50 & & SALVADOR & BA & III-IV & c & 2.8 & 4 & & (GAMA 1910) \\
\hline 6 & 1769 & 08 & $01:$ & 213 & 30 & 13.00 & 38.50 & & SALVADOR & $8 \mathrm{~A}$ & & c & & & & (MELLL 1881) ano 1767 ? \\
\hline 7 & 1808 & 08 & 08 & 08 & & 05.54 & 37.61 & 100 & Aşu & RN & $v_{I}$ & в & 4.8 & 3 & 230.0 & (CAPANEMA 1859) \\
\hline 8 & 1810 & 04 & 19 & & & 03.10 & 40.84 & & GRANJA & CE & & c & & & & (BRASIL 1863) \\
\hline 9 & 1811 & 10 & 28 & 19 & & 08.08 & 34.87 & 50 & RECIFE & PE & v & c & 3.8 & 3 & .6 & drea IV; (ALCANTARA 1860) \\
\hline 10 & 1815 & 06 & & & & 12.76 & 38.49 & & CABOTO & BA & & c & & & & (SAMPAIO 1916) \\
\hline 11 & 1824 & & & & & 07.59 & 39.28 & & JARDIM & CE & & c & & & & fratura $30 \mathrm{~km}$ ? (BRASIL1863) \\
\hline 12 & 1846 & & & & & 03.10 & 40.84 & & GRANJA & CE & & c & & & & (BRASIL 1863) \\
\hline 13 & 1852 & 12 & 02 & 133 & 30 & 04.56 & 37.76 & & ARACATI & CE & & c & & & & (CAPANEMA 1859) \\
\hline 14 & 1852 & & & & & 03.10 & 40.84 & & GRANJA & CE & & c & & & & (BRASIL 1863) \\
\hline 15 & 1854 & 01 & 10 & 07 & & 05.20 & 35.46 & & TOUROS & RN & v & c & 3.5 & 4 & & (CAPANEMA 1859) \\
\hline 16 & 1855 & & & & & 03.10 & 40.84 & & GRANJA & CE & & c & & & & (BRASIL 1863) \\
\hline 17 & 1864 & 11 & 23 & 113 & 30 & 02.53 & 44.30 & & SÃo LUfS & MA & IV-V & c & 3.2 & 4 & & (MELLLO 1881) \\
\hline 19 & 1871 & 04 & $05 \mathrm{c}$ & 013 & 30 & 03.40 & 44.35 & & ITAPICURU-M. & - MA & $v-v I$ & c & 3.7 & 4 & & (BRANNER 1912) \\
\hline 20 & 1871 & 06 & 14 & & & 02.53 & 44.30 & & $s \pi_{0}$ Luís & MA & & c & & & & (O AMERICANO 11.09 .1871$)$ \\
\hline 21 & 1879 & 07 & $24 \quad 1$ & 172 & 25 & 05.77 & 35.21 & 20 & NATAL & RN & v & c & 3.4 & 3 & 0.7 & (MEDEIROS 1965) \\
\hline 22 & 1886 & & & & & & & & LAJES & RN & & D & & & & (D. NATAL 29.08.63) \\
\hline 23 & 1894 & & & & & & & & LAJES & RN & & D & & & & $"$ \\
\hline & & & & & & & & & & & & & & & & (J.8. 20.08.68) \\
\hline & & & & & & & & & & & & & & & & (SAMPAIO 1920) \\
\hline
\end{tabular}

(SAMPAIO 1920) 


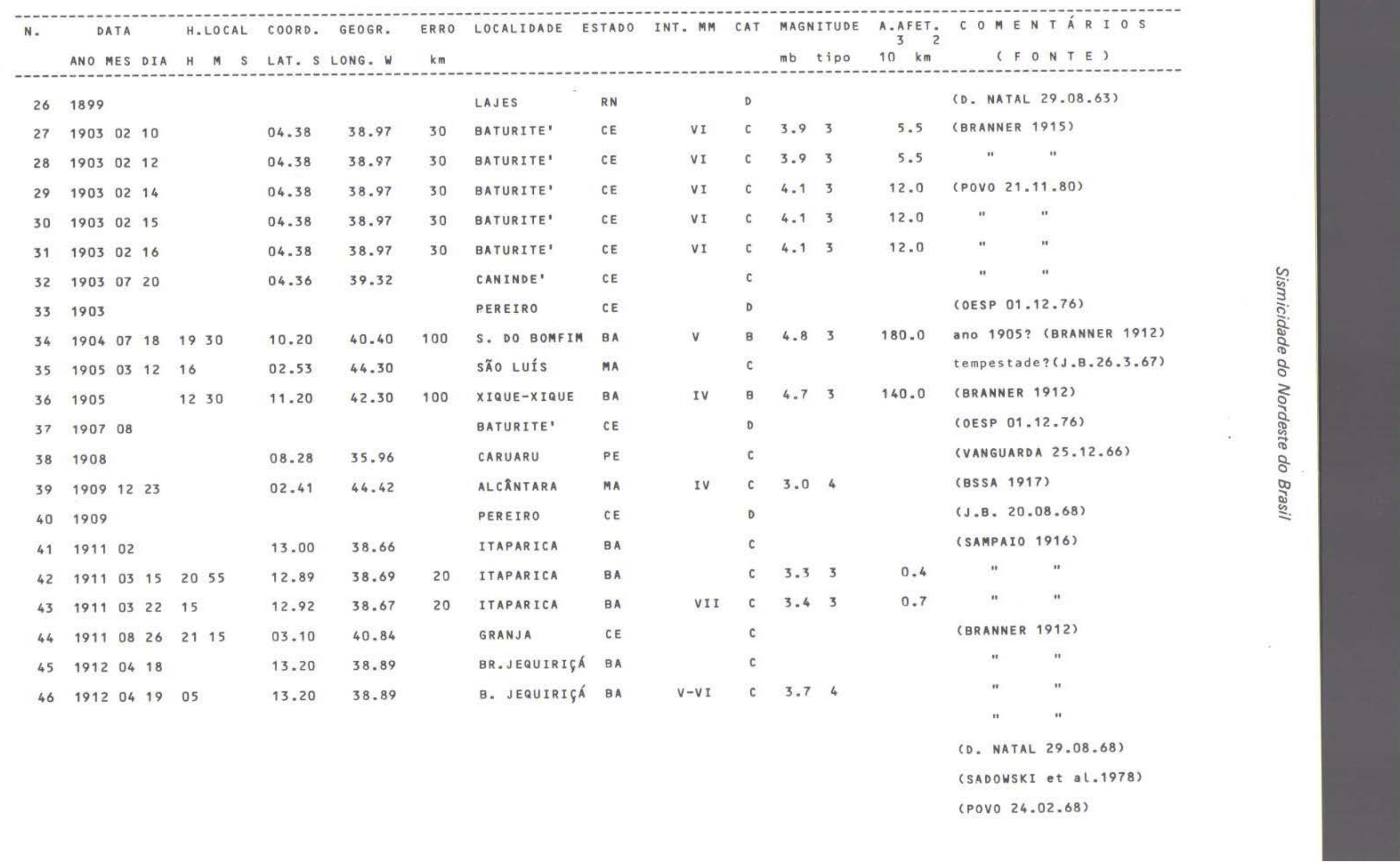




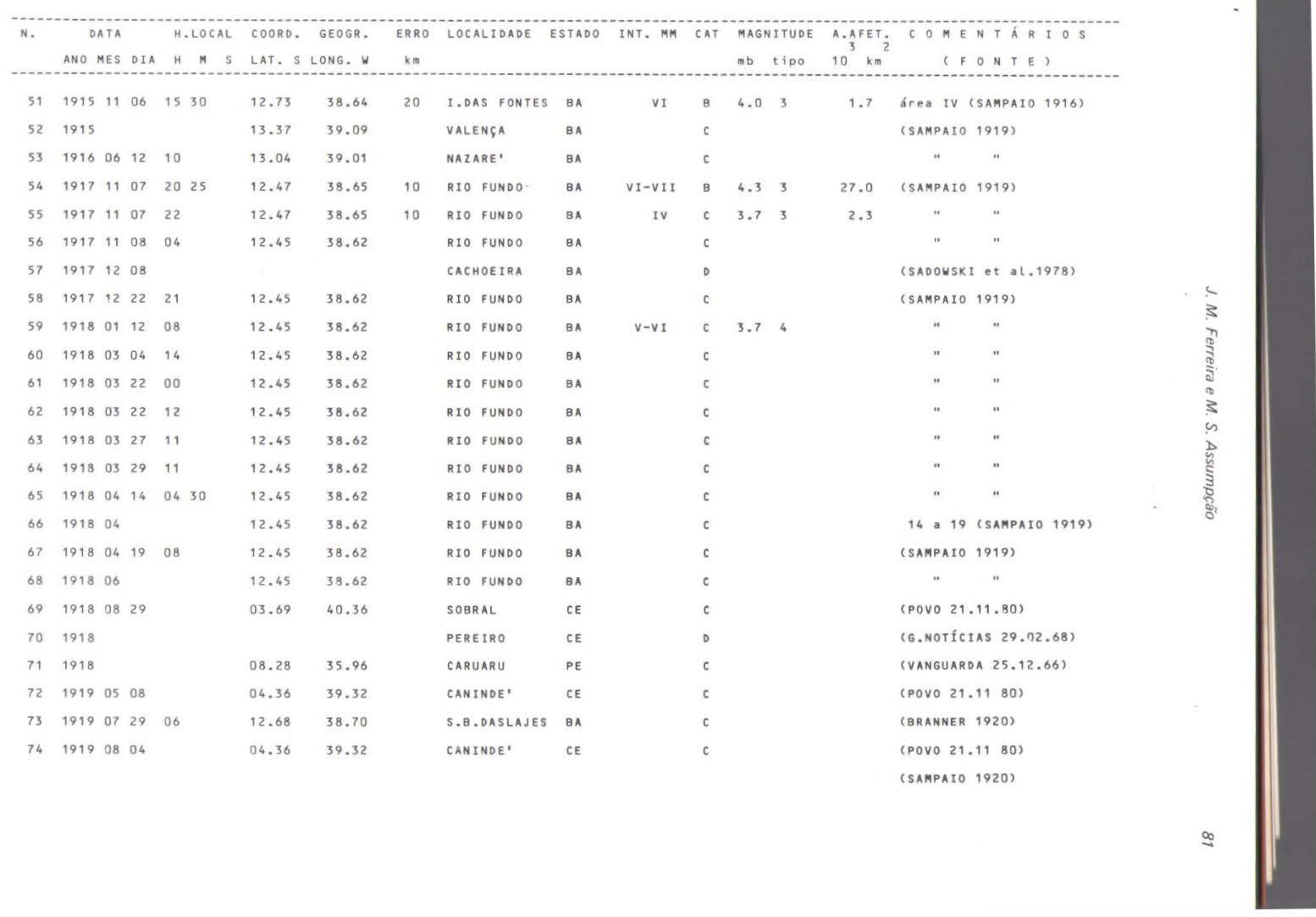




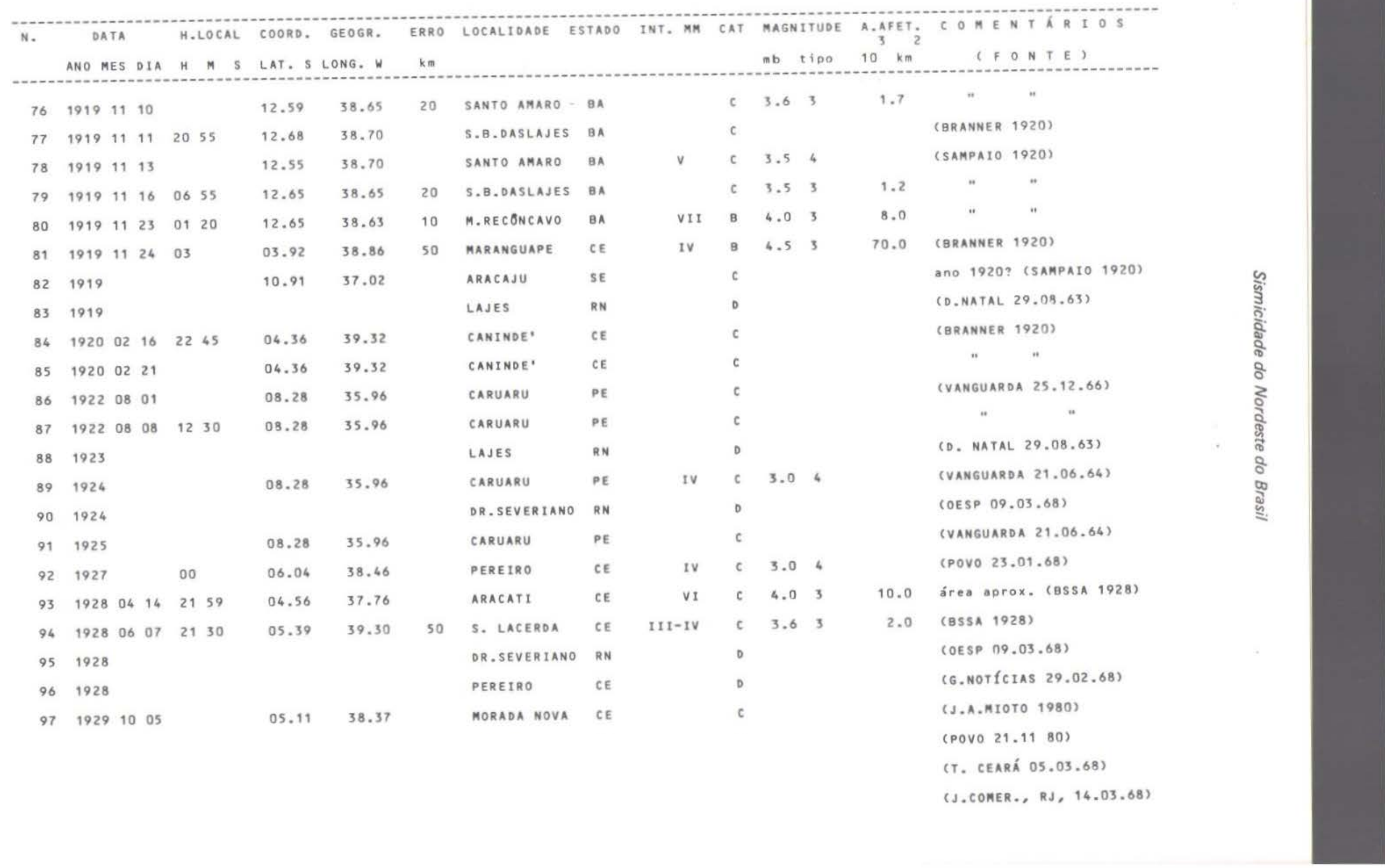




\begin{tabular}{|c|c|c|c|c|c|c|c|c|c|c|c|c|c|c|c|c|}
\hline N. & ANO & $\begin{array}{l}\text { ATA } \\
\text { MES }\end{array}$ & DIA & & $\begin{array}{l}\text { LOCAL } \\
M S\end{array}$ & $\begin{array}{l}\text { COORD. } \\
\text { LAT. S L }\end{array}$ & $\begin{array}{l}\text { GEOGR. } \\
\text { LONG. W }\end{array}$ & $\begin{array}{c}\text { ERRO } \\
k m\end{array}$ & LOCALIDADE & ESTADO & INT. MM & CAT & MAGN & $\begin{array}{l}\text { VITUDE } \\
\text { tipo }\end{array}$ & $\begin{array}{l}\text { A. AFET } \\
10^{3} \mathrm{~km}^{2}\end{array}$ & $\begin{aligned} \text { COM ENTÁRIOS } \\
\text { ( } F O N T E)\end{aligned}$ \\
\hline 101 & 1936 & & & & & & & & DR.SEVERIANO & $R N$ & & D & & & & (OESP 09.03 .68 ) \\
\hline 102 & 1938 & & & & & & & & PEREIRO & CE & & D & & & & (C. CEARA' 17.01 .68 ) \\
\hline 103 & 1938 & & & & & & & & UIRAUNA & PB & & D & & & & (POVO 24.02.68) \\
\hline 104 & 1940 & & & & & & & & DR.SEVERIANO & RN & & D & & & & (OESP 09.03 .68$)$ \\
\hline 105 & 1940 & & & & & & & & PEREIRO & CE & & D & & & & (T. CEARA' 05.03.68) \\
\hline 106 & 1942 & & & 153 & 30 & 03.10 & 40.84 & & GRANJA & CE & IV & c & 3.0 & 4 & & (FSP 21.11 .80$)$ \\
\hline 107 & 1943 & & & & & & & & PEREIRO & CE & & D & & & & (G.NOTICIAS 29.02 .68 ) \\
\hline 108 & 1947 & 11 & 18 & & & 05.11 & 38.37 & & MORADA NOVA & CE & & c & & & & (J.A.MIOTO 1980) \\
\hline 109 & 1948 & & & & & & & & PEREIRO & CE & & D & & & & (FSP 01.03 .63 ) \\
\hline 110 & 1949 & 12 & 31 & & & 05.69 & 36.24 & & LAJES & RN & VI & c & 3.9 & 4 & & (D. NATAL 29.08 .63$)$ \\
\hline 111 & 1949 & & & & & & & & & AL & & D & & & & (OESP 18.01.62) \\
\hline 112 & 1950 & 04 & 07 & 12 & & 05.90 & 35.61 & & JOÃO CAMARA & RN & IV & c & 3.0 & 4 & & (D. NATAL 24.07 .73 ) \\
\hline 113 & 1954 & & & & & 09.93 & 36.49 & & JUNQUE IRO & AL & IV & c & 3.0 & 4 & & (G.ALAGOAS 07.03 .72$)$ \\
\hline 114 & 1958 & & & & & & & & IBARETAMA & CE & & D & & & & (T. CEARA' 31.07 .76$)$ \\
\hline 115 & 1961 & 05 & & & & 08.28 & 35.96 & & CARUARU & PE & & c & & & & (DEFESA 25.01.64) \\
\hline 116 & 1963 & 03 & 30 & & & 05.69 & 36.24 & & LAJES & RN & & c & & & & (D. NATAL 30.08 .63$)$ \\
\hline 117 & 1963 & 08 & 27 & & & 05.69 & 36.24 & & LAJES & RN & $V-V I$ & c & 3.7 & 4 & & (J.8. 26.03 .67$)$ \\
\hline 118 & 1963 & 09 & 03 & & & 05.69 & 36.24 & & LAJES & RN & & c & 3.7 & 3 & 3.0 & sent.J.Câmara? (JB26.3.67) \\
\hline 119 & 1963 & 10 & 02 & & & 05.69 & 36.24 & & LAJES & RN & VI & c & 3.9 & 4 & & (D. PE. 23.01.64) \\
\hline 120 & 1963 & & & & & 08.28 & 35.96 & & CARUARU & PE & & c & & & & (J.B. 26.03 .67$)$ \\
\hline 121 & 1964 & 01 & 19 & 11 & & 08.28 & 35.96 & & CARUARU & PE & v & c & 3.5 & 4 & & (D. NOITE 21.01.64) \\
\hline 122 & 1964 & 01 & 20 & & & 08.28 & 35.96 & & CARUARU & PE & & c & & & & $"$ \\
\hline 123 & 1964 & 06 & 16 & & & 08.28 & 35.96 & & CARUARU & $P E$ & v & c & 3.5 & 4 & & $\begin{array}{l}\text { (D. NOITE 16.06.64) } \\
\text { (OESP 13.07.76) }\end{array}$ \\
\hline
\end{tabular}

(POVO 24.05.69) 


\begin{tabular}{|c|c|c|c|c|c|c|c|c|c|c|c|c|c|c|c|c|c|}
\hline N. & & ATA & & & LOC & & COORD. & GEOGR. & ERRO & LOCALIDADE E & ESTADO & INT. MM & CAT & MAGN & VITUDE & A. AFET; & C OMENTARIOS \\
\hline & ANO M & MES & DIA & H & $M$ & s & LAT. $S$ & LONG. W & $\mathrm{km}$ & & & & & $m b$ & tipo & $10 \mathrm{~km}$ & ( FONTE) \\
\hline 126 & 1965 & & & & & & 08.20 & 35.98 & & CARUARU & PE & & c & & & & (J.8. 26.03 .67 ) \\
\hline 127 & 1967 & 01 & 21 & 155 & 59 & 48 & 08.20 & 35.98 & 10 & CARUARU & PE & v & B & 3.8 & 1 & 7.0 & (NAT; D. NOITE 26.01.67) \\
\hline 128 & 1967 & 01 & 24 & & & & 08.23 & 35.96 & & CARUARU & PE & & c & & & & (D. NOITE 26.01 .67 ) \\
\hline 129 & 1967 & 01 & 25 & & & & 08.28 & 35.96 & & CARUARU & $P E$ & & c & & & & $"$ \\
\hline 130 & 1967 & 01 & 26 & & & & 08.28 & 35.96 & & CARUARU & PE & & c & & & & $"$ \\
\hline 131 & 1967 & 04 & 03 & 07 & 18 & 23 & 02.00 & 46.00 & 500 & MARANHÃO ? & MA & & I & 4.7 & 0 & & (ISC) NAT năo registrou \\
\hline 132 & 1968 & 01 & 12 & 22 & 55 & 51 & 06.09 & 38.44 & 10 & PEREIRO & CE & vi & c & 3.9 & 2 & 25.0 & (NAT; C.CEARA' 17.01.68) \\
\hline 133 & 1968 & 01 & 12 & 22 & 58 & & 06.04 & 38.46 & & PEREIRO & CE & III-IV & c & 2.8 & 4 & & (POVO 16.01.68) \\
\hline 134 & 1968 & 01 & 18 & 07 & 40 & & 06.09 & 38.44 & & SALAO & RN & $v$ & c & 3.5 & 4 & & dia 18? (Povo 19.01.68) \\
\hline 135 & 1968 & 01 & 18 & 08 & & & 06.09 & 38.44 & & SALÃO & RN & & c & & & & dia 18 ? \\
\hline 136 & 1968 & 01 & 18 & 08 & 55 & & 06.09 & 38.44 & & SALAOO & RN & & c & & & & dia 18? " \\
\hline 137 & 1968 & 01 & 19 & & & & 06.04 & 38.46 & & PEREIRO & CE & & c & & & & (G. NOTÍCIAS 21.01.68) \\
\hline 138 & 1968 & 02 & 04 & & & & 06.11 & 38.44 & & JUNCO & RN & IV - V & c & 3.2 & 4 & & (POVO 07.02 .68 ) \\
\hline 139 & 1968 & 02 & 15 & 10 & 20 & 48 & 06.09 & 38.44 & 10 & PEREIRO & CE & VII-VII & B & 4.1 & 2 & 11.0 & (NAT; POVO 24.02.68) \\
\hline 140 & 1968 & 02 & 23 & 11 & 23 & 02 & 06.09 & 38.44 & 5 & PEREIRO & CE & VII & A & 4.6 & 2 & 84.0 & (NAT, IAG, ISC; \\
\hline 141 & 1968 & 02 & 23 & 11 & 37 & 01 & 06.09 & 38.44 & 10 & PEREIRO & CE & & I & 3.0 & 1 & & (NAT) epicentro inferido \\
\hline 142 & 1968 & 02 & 23 & 12 & 21 & 16 & 06.09 & 38.44 & 10 & PEREIRO & CE & & I & 3.0 & 1 & & (NAT) epicentro inferido \\
\hline 143 & 1968 & 02 & 23 & 12 & 33 & 03 & 06.09 & 38.44 & 10 & PEREIRO & CE & & c & 3.8 & 2 & & (NAT; POVO 24.02 .68 ) \\
\hline 144 & 1968 & 02 & 25 & 00 & & & 06.04 & 38.46 & & PEREIRO & CE & & c & & & & (D. NOITE 28.02 .68 ) \\
\hline 145 & 1968 & 02 & 25 & 00 & 05 & & 06.04 & 39.46 & & PEREIRO & CE & & c & & & & (FSP 01.03 .68 ) \\
\hline 146 & 1968 & 02 & 25 & 01 & & & 06.04 & 38.46 & & PEREIRO & CE & & c & & & & (POVO 28.02.68) \\
\hline 147 & 1968 & 02 & 25 & 07 & & & 06.09 & 38.44 & & S.DOSMACACOS & RN & & c & & & & $"$ \\
\hline
\end{tabular}

(6. NOTfCIAS 29.02.68)

(OESP 05.03.68) 


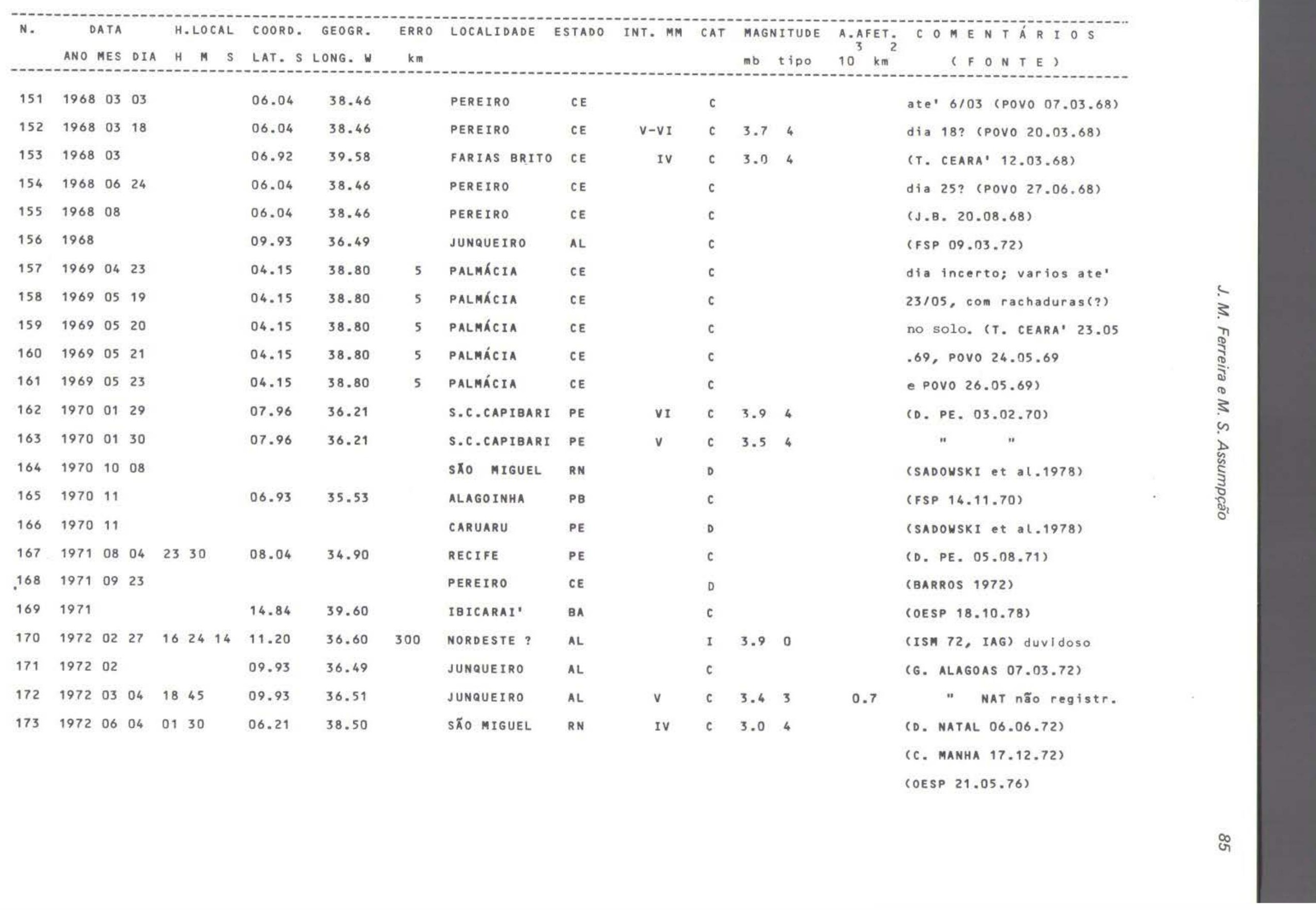




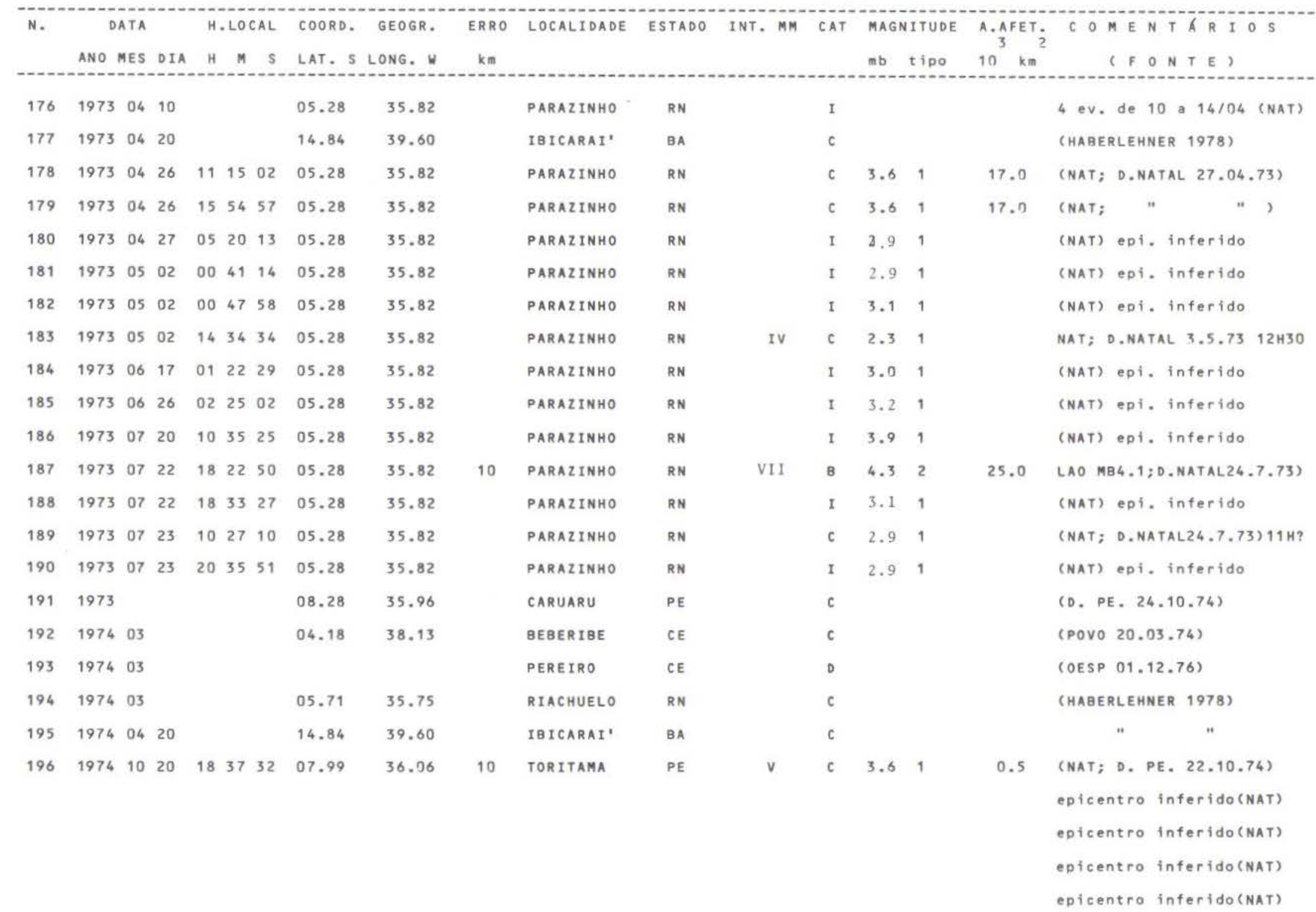




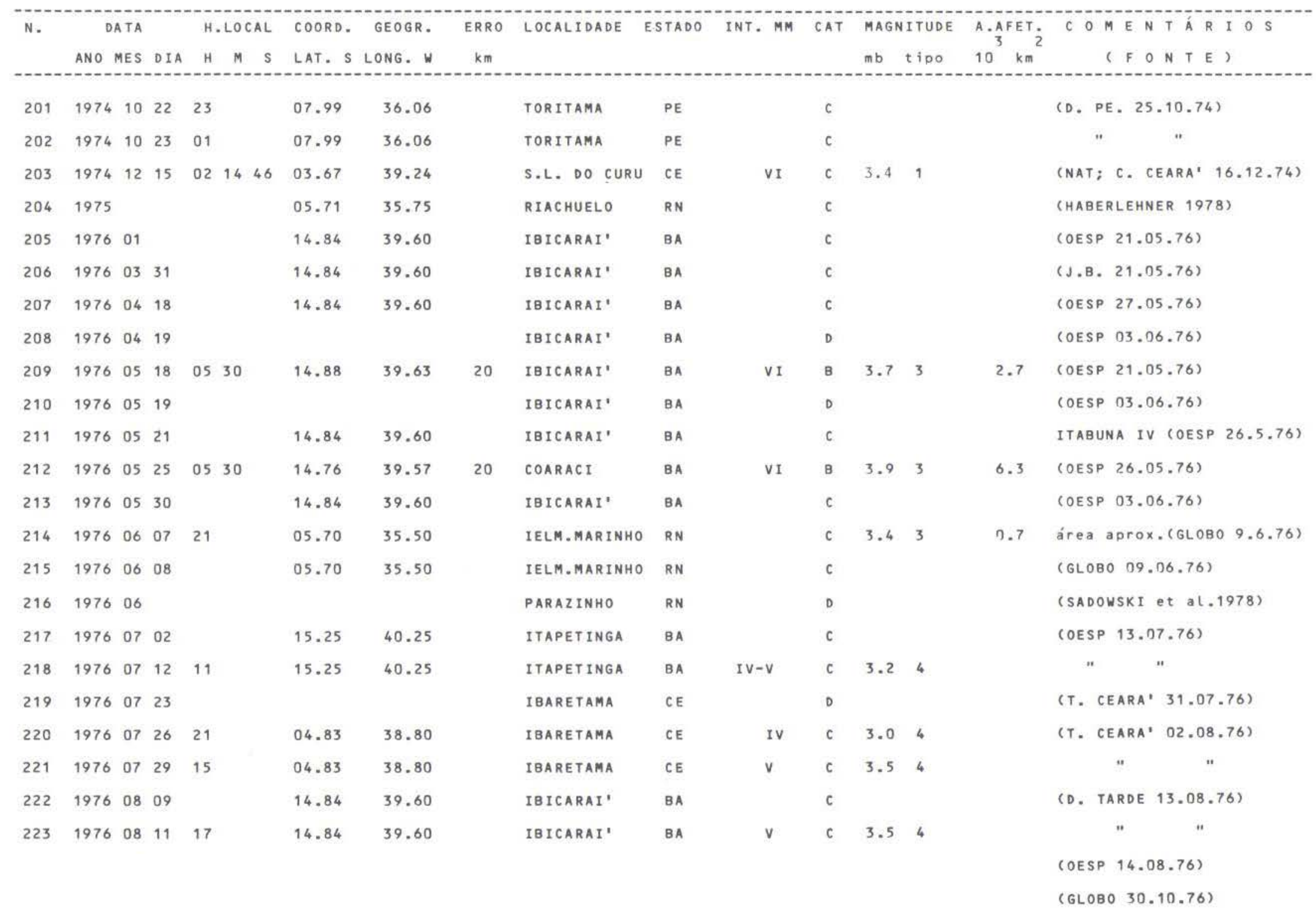




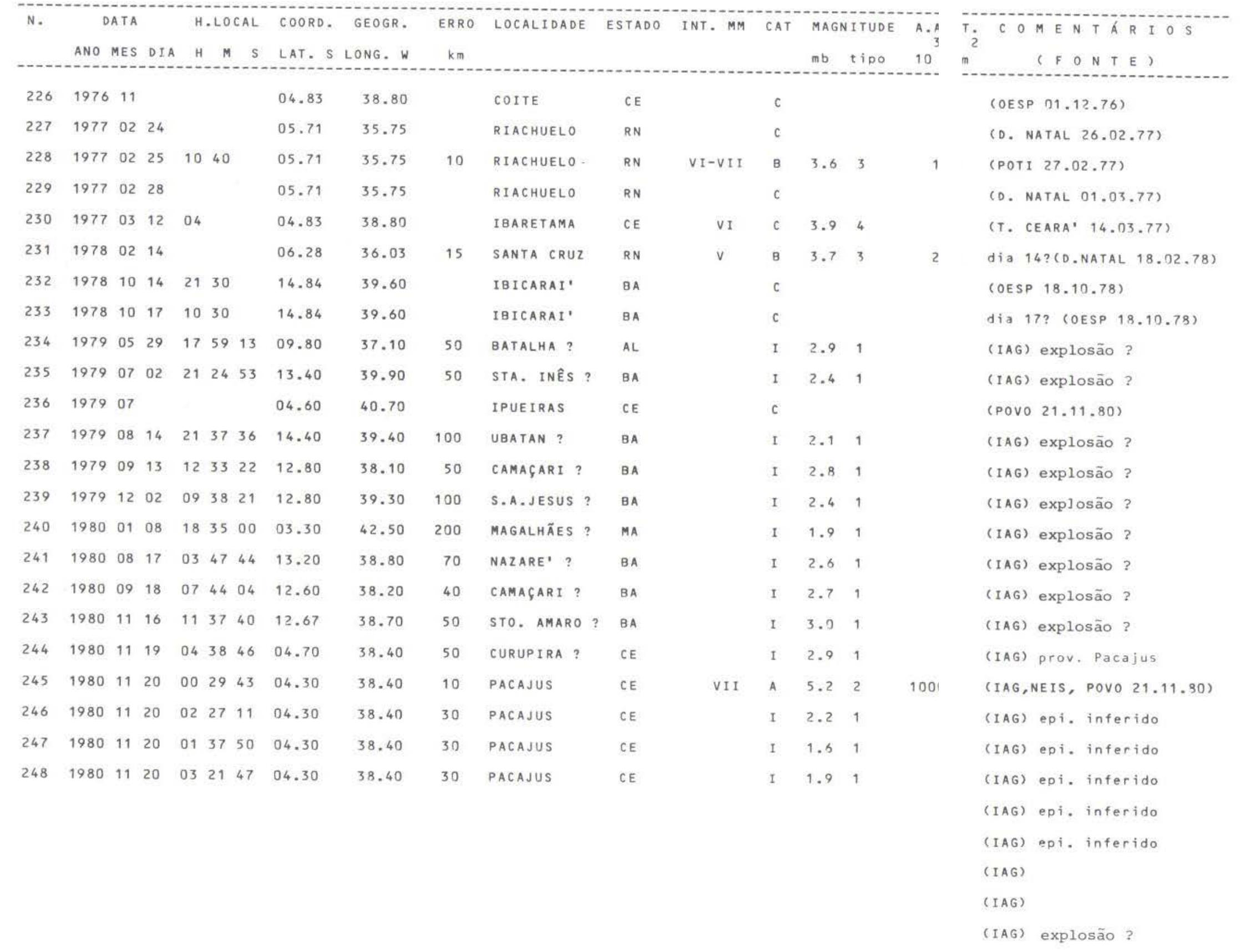

